\title{
Ejecución de la pena de prisión de adultos en Alemania: análisis de las leyes estaduales a la luz de la Ley Federal de 1976 y la jurisprudencia del Tribunal Constitucional Federal Alemán (BVerfG) Adult Prison Law in Germany: Analysis of State Laws in the Light of the Federal Law of 1976 and German Federal Constitutional Court's (BVerfG) Case Law
}

\author{
ÁLVARO CASTRO MORALES** \\ Universidad de Chile (Chile)
}

Resumen: El artículo estudia algunos de los cambios legislativos producidos a partir de la reforma de 2006 en materia de ejecución de la pena de prisión de adultos en Alemania. El presente artículo indaga si las nuevas legislaciones estaduales en materia de ejecución de la pena de prisión de adultos recogen los lineamientos de la Ley Federal de 1976 y los estándares jurisprudenciales del Tribunal Constitucional Federal Alemán (BVerfG) en la materia. Se busca conocer en qué temáticas los criterios de la ley federal y jurisprudencia del BVerfG influyen en las legislaciones estaduales, así como las temáticas donde las leyes estaduales han innovado con soluciones distintas a las planteadas por la ley federal y la jurisprudencia del BVerfG. También se pretende hacer un análisis crítico acerca de si dicha adhesión o distanciamiento de las leyes estaduales significa o no un avance con respecto a la normativa anterior.

Palabras clave: leyes de ejecución de la pena de prisión en Alemania, reforma de 2006, Ley Federal de 1976, estándares jurisprudenciales del BVerfG en materia de privados de libertad

\begin{abstract}
The article examines some of the legislative changes of the 2006 reform of adult prisons Law in Germany. The 2006 reform gave the Länder competence to regulate the execution of the prison sentence, generating a wave of new prison laws in the country. This article examines whether the new legislation regarding the adult prison sentences reflects the lineages of the federal law of 1976 and the case law standards of the BVerfG in this area. The aim is to know the issues where the criteria of federal law and BVerfG's case-law influence state legislation, on the other hand, the issues where state laws have innovated. At the same time, it also intends to make a critical
\end{abstract}

* Este artículo es producto de una pasantía de investigación realizada en enero de 2018 en el centro de criminología de la Ernst-Moritz-Arndt Universität Greifswald, Alemania. Agradezco a mi anfitrión Prof. Dr. Em. Frieder Dünkel por su atenta colaboración en la realización de este artículo.

** Profesor investigador jornada completa de la Facultad de Derecho de la Universidad de Chile. Doctor por la Universidad Ernst-Moritz-Arndt Universität Greifswald, Alemania.

Código ORCID: 0000-0002-9571-7172. Correo electrónico: acastro@derecho.uchile.cl 
analysis of whether the adherence or innovation of state laws signifies an advance with respect to previous regulations.

Key words: prison laws in Germany, 2006 reform, prison federal law of 1976, case law standards of the BVerfG

\begin{abstract}
CONTENIDO: I. INTRODUCCIÓN.- II. ESCENARIO LEGISLATIVO POSTERIOR A LA REFORMA DE 2006.- III. REGULACIÓN DE LAS LEYES ESTADUALES A LA LUZ DE LA LEY FEDERAL DE 1976 Y LA JURISPRUDENCIA DEL BVERG.- III.1. ESTATUS JURÍDICO DEL PRIVADO DE LIBERTAD.- III.2. CONTROL JUDICIAL.- III.3. FIN DE LA EJECUCIÓN DE LA PENA DE PRISIÓN.- III.4. SALIDAS O FLEXIBILIZACIÓN DE LA PRISIÓN.- III.5. CONTACTO CON EL MUNDO EXTERIOR.- III.6. TRATAMIENTO Y SU CONTENIDO.- III.7. MEDIDAS DISCIPLINARIAS.- III.8. MEDIDAS DE SEGURIDAD GENERALES.- III.9. MEDIDAS DE SEGURIDAD ESPECIALES.III.10. TIPOS DE CENTROS Y SECCIONES.- III.11. TRABAJO EN EL INTERIOR DE PRISIÓN.- IV. CONCLUSIONES Y DISCUSIÓN.
\end{abstract}

\title{
I. INTRODUCCIÓN
}

El 7 de julio de 2006 tuvo lugar la más significativa reforma de la Constitución Federal alemana (en adelante, GG como abreviación de Grundgesetz) que establece una nueva distribución de competencias entre la federación y los estados federados (Länder). Como explica Martín Vida, la madre de todas las reformas toca la estructura del modelo federal alemán, busca superar el centralismo y el escaso protagonismo que tenían los Länder (Martín Vida, 2006, pp. 337- 339).

El contenido de la reforma fue variado, se centró en la reducción del número de Zustimmungsgesetze ${ }^{1}$ y en la reducción de las competencias legislativas de la federación. En lo que a este trabajo interesa, el nuevo reparto de competencias entre la federación y los Länder tocó, entre otras materias, la ejecución de las penas. De esta manera, el derecho de reunión, el horario de cierre de comercios, la enseñanza superior y universitaria, y la ejecución de la pena, entre otros asuntos que antes eran objeto de legislación federal sobre la base del artículo 74.1 de la GG, pasaron con la reforma a ser competencia exclusiva de los Länder (Martín Vida, 2006, p. 346).

La reforma del federalismo alemán de 2006 generó, en el ámbito de la ejecución de la pena de prisión, una nueva etapa que impulsaría nuevas leyes de ejecución de la pena de prisión, prisión preventiva y custodia de seguridad en Alemania, más 60 leyes en total, como señala Cornel (2018, p. 16). El traspaso de la ejecución de la pena de prisión del ámbito federal al estadual generó una serie de críticas por parte de la doctrina

1 Leyes federales que necesitan contar con la aprobación del Consejo Federal (Bundesrat) para ser aprobadas. Para mayor detalle, véase Martín Vida (2006, p. 338). 
y operadores. Se observó que la reforma fue apresurada y sin el debate necesario y que quebraría la unificación de la ejecución de la pena de prisión que tanto había costado ${ }^{2}$. En los hechos, las manifestaciones contrarias a la reforma no se hicieron esperar, en una carta abierta, doce ex ministros de Justicia, de ámbito federal y estadual, de diferentes partidos políticos, expresaron su abierta oposición a la reforma y llamaron a enmendar el camino, por ejemplo, Lore Maria PeschelGutzeit, Sabine Leutheusser-Schnarrenberger, Herta Däubler-Gmelin, Hans Otto Bräutigam, Christian Pfeiffer, Eberhard Diepgen, Wolfgang Wieland, Rupert von Plottnitz y Klaus Klingner. En el mismo sentido, 120 especialistas en temas penitenciarios y criminológicos, entre ellos destacados profesores como Frieder Dünkel y Schüler-Springorum ${ }^{3}$, se oponían a la reforma (Cornel, 2018, pp. 16-17). En los hechos no fue extraño encontrar en la doctrina expresiones como «iHacia dónde se dirige la justicia penitenciaria? (Wohin fährt der Justizvollzug?)»(Koop \& Kappenberg, 2009).

2 La unificación de la ejecución de la pena de prisión se logró en Alemania con la Ley Federal de 1976. Previo a dicho hito existieron variados intentos fallidos. La disparidad de criterios y realidades en las distintas regiones motivó el Proyecto para unificar la regulación de la ejecución de la sanción privativa de libertad de 1879 que innova con la incorporación del principio de separación entre adultos y adolescentes; la consagración expresa de derechos como el de visita, el derecho a realizar reclamos; a recibir correspondencia, y a la libre práctica religiosa. El segundo intento se genera con la expedición de los Principios del Consejo de Estado, aprobados en 1897, que recogen buena parte de las ideas del proyecto de unificación de 1879 ampliando el principio de separación para hombres y mujeres y contemplando un máximo de doce horas de trabajo dentro de los centros cerrados (Kaiser \& Schöch, 2002, p. 42). Los principios para la ejecución de la sanción privativa de libertad de 1923, iniciativa del ministro de Justicia Gustav Radbruch, constituyen el tercer intento. Se reconoce en su contenido una marcada influencia de los Principios de 1897 y se incorpora una serie de innovaciones que para la época son consideradas revolucionarias. Por primera vez se habla de fines en la etapa de la ejecución de la sanción privativa de libertad, representados por el orden, trabajo y puntualidad. Adicionalmente, se pone hincapié en el trato digno y humanitario de los presos (Vormbaum, 2009, p. 181).

3 En Alemania, la ejecución de la sanción de prisión se encuentra inmersa, al igual que el derecho penal juvenil y sanciones penales, dentro de la criminología. La criminología alemana es una disciplina autónoma con una comunidad, manualística e investigaciones consolidadas. La carta de los 120 especialistas representa la opinión de un grupo científico maduro que se pronuncia en torno a la reforma de 2006. Para entender la evolución de la criminología alemana es necesario tener presente que, después de la década de 1950, proliferan en el país las publicaciones referentes a criminalidad juvenil, praxis de sanciones y cárceles. En materia carcelaria, y en medio de lo que la doctrina llamaba la desolación del sistema carcelario (Dünkel, 1996, pp. 2-3), destacan los trabajos centrados en los efectos del encierro, la cárcel como problema sociológico, fines de la ejecución y cárceles juveniles. Las investigaciones más destacadas de la época en el ámbito carcelario fueron las obras de Ohm, Persönlichkeitswandlung unter Freiheitsentzug (1964); Matthes, Die Soziologie des Gefangenen als existenzielles Problem (1956); Hofmann, Jugend im Gefängnis (1967); Hoppensack, Über die Strafanstalt und ihre Wirkung auf Einstellung und Verhalten von Gefangenen (1969); Deimling, Theorie und Praxis des Jugendstrafvollzugs in pädagogischer Sicht (1969); y Waldmann, Zielkonflikte in einer Strafanstalt (1968) (al respecto, véase Göppinger, 1997, pp. 23-26). Adicionalmente al aporte de Callies, Kaiser, Döllinger, Schöch y Kerner con sus investigaciones comparadas, hay que considerar la nueva generación de criminólogos que formaron, entre otros, Dünkel, Böhm, Jehle y Albrecht, quienes con entusiasmo le dieron las credenciales de mayoría de edad a la ejecución de la sanción penal con una comunidad que está presta para aportar hasta el día de hoy al desarrollo de la temática. A esta comunidad de especialistas pertenecieron también destacados intelectuales del derecho que desde sus cátedras apoyaron a lo largo de la historía al desarrollo de la ejecución de la sanción de prisión, valga un reconocimiento a Carl Joseph Anton Mittermaier, Franz von Holtzendorff, Berthold Freudenthal, Gustav Radbruch, Harmin Kauffman, Georg Rusche, Otto Kirchheimer, entre otros (véase Kaiser \& Schöch, 2002, pp. 42-43; Vormbaum, 2009, p. 112).

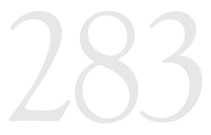

EJECUCIÓN DE LA PENA DE PRISIÓN

DE ADULTOS EN

ALEMANIA: ANÁLISIS

DE LAS LEYES

ESTADUALES A

LA LUZ DE LA LEY

FEDERAL DE 1976 Y

LA JURISPRUDENCIA

DEL TRIBUNAL

CONSTITUCIONAL

FEDERAL ALEMÁN

(BVERFG)*

ADULT PRISON

LAW IN GERMANY:

ANALYSIS OF STATE

LAWS IN THE LIGHT

OF THE FEDERAL

LAW OF 1976 AND

GERMAN FEDERAL

CONSTITUTIONAL

COURT'S (BVERFG)

CASE LAW 
La reforma de 2006 se inserta en un escenario que estaba circunscrito por una ley federal que había recibido reconocimiento generalizado dentro y fuera de Alemania y por una consistente jurisprudencia en materia de privados de libertad del Tribunal Constitucional Federal alemán (en adelante, BVerfG, como abreviación de Bundesverfassungsgericht). Cabe recordar que la última gran reforma al sistema de la ejecución de la pena de prisión de adultos había tenido lugar en la década de 1970 con la ley sobre ejecución de la pena privativa de libertad y de las medidas privativas de libertad de mejoramiento (en adelante, Ley Federal de 1976). Dicha ley marcó un hito y fue considerada, en el plano europeo, un referente en la materia y dentro de Alemania como una «piedra angular» o un «gran avance en el sistema penal» (Kaiser \& Schöch, 2003, p. 62), además que se insertaba dentro de un moderno sistema de sanciones ${ }^{4}$ que le otorgaba un gran protagonismo a la pena de multa y a la suspensión de la pena de prisión ${ }^{5}$, generando en la práctica una carga de trabajo bastante reducida para la institución penitenciaria. Después de la gran reforma penal de 1969 la multa ha cubierto más del 80\% de las sanciones impuestas en el sistema penal alemán, la suspensión de la pena de prisión cerca del 15\% y la pena de prisión efectiva cerca del 5\%. Desde la década de 1970 hasta nuestros días, dichos porcentajes se han mantenido estables6 (Dünkel, 2018, pp. 413-416; Neubacher, 2017, p. 147).

Por otro lado, el BVerfG ha tenido en los últimos cuarenta y cinco años una gran importancia en el tema de la ejecución de la sanción privativa de libertad y ha fijado un marco mínimo dentro del cual se inserta la actividad penitenciaria. Su jurisprudencia se ha construido sobre la base de los principios de la dignidad humana y el Estado social y democrático

4 La pena privativa de libertad, artículo 38 del Código Penal alemán (en adelante, StGB) se contempla solo para casos de mediana gravedad, gravedad y multirreincidencia. La pena de prisión bajo el StGB tiene dos modalidades, la temporal y la perpetua. La pena privativa de libertad temporal está concebida para un máximo de 15 años. Luego de la abolición de la pena de muerte en 1949, la pena perpetua pasó a ser la sanción más dura del sistema, pese a las críticas en torno a la vulneración de la dignidad humana, proporcionalidad e ineficacia (Dünkel, 2013a, p. 1697). En el diseño del Código Penal alemán, la pena de prisión junto con la multa (artículo $40 \mathrm{StGB}$ ) son consideradas sanciones y sanciones principales. Adicionalmente, es posible encontrar las categorías consecuencias accesorias del delito; y medidas de corrección y seguridad. Dentro de las sanciones se contempla además una segunda clasificación, las accesorias (ver Neubacher, 2017, p. 145).

5 Según explican Salinero, Morales Peillard y Castro Morales, «La suspensión condicional de la ejecución de la pena de prisión se regula en los Artículos 56 a 58 del StGB y está estructurada en tres grados. i). La suspensión condicional de penas de prisión inferiores a seis meses; ii). La suspensión condicional de penas de prisión entre seis y un año; y c). La suspensión de penas de prisión entre uno hasta dos años» (2017, p. 841).

6 En cuanto a la tasa de privados de libertad por 100000 habitantes, según el International Center for Prison Studies, Alemania - con una tasa de 80 - forma parte del grupo de países con bajas tasas de privados de libertad junto con Finlandia, 55; Suecia, 53; Noruega, 74; Dinamarca, 58; Irlanda del Norte, 80; Eslovenia, 63; Italia, 86 y Bosnia, 73 (Dünkel, 2013a, p. 1709). Téngase presente que la doctrina distingue, en cuanto a tasas de privados de libertad por 100000 habitantes, países con baja tasa «hasta 100 por 100000 habitantes", moderada «entre 100 a 150" y extrema "superior a 150 ». En los bordes se encuentran Islandia, con una tasa de 45, y Rusia con 443 (información correspondiente a 2017 recuperada del sitio web del International Center for Prison Studies: http:// www.prisonstudies.org/map/europe). 
de Derecho. No se olvide que el BVerfG, a través de su jurisprudencia, se ha pronunciado sobre la lógica de la relación de sujeción especial, ha impulsado la modernización de la normativa en la ejecución de las sanciones penales de los adultos y adolescentes, ha profundizado sobre el fin de la sanción penal en la etapa de ejecución, ha determinado el contenido básico de las actividades laborales dentro de los recintos penitenciarios, ha exigido la libertad condicional en la pena perpetua, y ha reafirmado la especialidad en la ejecución de las sanciones privativas de libertad de los adolescentes?

El presente artículo tiene por objeto indagar si las nuevas legislaciones estaduales en materia de ejecución de la pena de prisión de adultos recogen los lineamientos de la Ley Federal de 1976 y los estándares jurisprudenciales del BVerfG en la materia. Se busca conocer en qué temáticas los criterios de la ley federal y jurisprudencia del BVerfG influyen sobre las legislaciones estaduales, así como las temáticas donde las leyes de los Länder han innovado con soluciones distintas a las planteadas por la ley federal y la jurisprudencia del BVerfG. También se pretende hacer un análisis crítico acerca de si dicha adhesión o distanciamiento de las leyes estaduales significa o no un avance con respecto a la normativa anterior.

Es importante mencionar que el artículo tiene un carácter exploratorio y no busca acabar la discusión. En este sentido, el análisis que se propone se concentra solo en los aspectos centrales de las legislaciones estaduales que dicen relación con los fines, estatus jurídico del preso, control judicial, medidas disciplinarias, medidas de seguridad, tratamiento, trabajo, flexibilización de la sanción, contacto con el mundo exterior y tipos de centros. También es necesario considerar que el artículo solo se focalizará en las leyes de ejecución de la pena de prisión de adultos, no considerando en su análisis la normativa de la ejecución de la pena de prisión juvenil, prisión preventiva y custodia de seguridad. Estos temas, por su complejidad, merecen un estudio en sí mismo.

Para lo anterior, el artículo será dividido en tres secciones. La primera (II) explicará el escenario legislativo posterior a la reforma de 2006, para entender en términos generales cómo ha quedado regulada la materia después de dicha reforma y cómo se desplegaron las estrategias legislativas de los Länder. En la siguiente sección (III), tendrá lugar el análisis central del artículo, y abordará los fines de la ejecución, estatus jurídico del preso, control judicial, medidas disciplinarias, medidas de seguridad, tratamiento, trabajo, flexibilización de la sanción, contacto con el mundo exterior y tipos de centro. En cada uno de estos temas se describirá cuáles han sido los lineamientos principales fijados por la

EJECUCIÓN DE LA PENA DE PRISIÓN DE ADULTOS EN ALEMANIA: ANÁLISIS DE LAS LEYES ESTADUALES A LA LUZ DE LA LEY FEDERAL DE 1976 Y LA JURISPRUDENCIA DELTRIBUNAL CONSTITUCIONAL FEDERAL ALEMÁN (BVERFG)*

ADULT PRISON LAW IN GERMANY: ANALYSIS OF STATE LAWS IN THE LIGHT OF THE FEDERAL LAW OF 1976 AND GERMAN FEDERAL CONSTITUTIONAL COURT'S (BVERFG) CASE LAW 
Ley Federal de 1976, los estándares jurisprudenciales del BVerfG y la solución adoptada por las leyes estaduales.

Por último, en la parte IV y sobre la base de los alcances y planteamientos obtenidos previamente, procederemos a responder las preguntas en torno a si las nuevas legislaciones estaduales en materia de ejecución de la pena de prisión de adultos recogen los lineamientos de la Ley Federal de 1976 y los estándares jurisprudenciales del BVerfG en la materia. Adicionalmente, se busca abordar críticamente si la influencia de la ley federal y jurisprudencia del BVerfG en las leyes estaduales y la innovación que han presentado los Länder en sus leyes significan un avance con respecto del estado normativo previo. Asimismo, se pretende destacar aquellos aspectos de la reforma de 2006 que podrían ser considerados en futuras reformas en nuestros países.

\section{ESCENARIO LEGISLATIVO POSTERIOR A LA REFORMA DE 2006}

Antes de la reforma de 2006, la ejecución de la pena de prisión de adultos se encontraba regulada a escala federal por la ley de 1976 «Strafvollzugsgesetz» ${ }^{8}$. La Ley Federal de 1976 tuvo un alcance limitado y solo reguló la ejecución de la pena de prisión de los adultos (Böhm, 2005). Para los adolescentes la situación fue muy diferente y debieron transcurrir 35 años para lograr que la temática fuera regulada por una ley y bajos las lógicas de la Convención de los Derechos de los Niños. Durante dicho periodo, un reglamento denominado «Verwaltungsvorschriften zum Jugendstrafvollzug» reguló la actividad (Ostendorf, 2012, pp. 29-339.

El panorama normativo de la ejecución de la pena de prisión de los adultos en Alemania, después de la reforma de 2006, se compone de dos niveles: federal y estadual. En el plano federal, la ley de ejecución

8 La Ley Federal de 1976 se enmarca dentro de un movimiento regional de reforma de la ejecución de la pena de prisión que busca abandonar la regulación basada en reglamentos y la filosofía decimonónica del privado de libertad como súbdito de la administración penitenciaria que solo tiene obligaciones. Al igual que España, Grecia, Austria, Noruega, Japón, Holanda e Italia, Alemania decide regular el tema en una ley especial de ejecución de la sanción privativa de libertad. Francia, Polonia, Portugal y Rusia, en cambio, regulan la temática en sus códigos procesales penales. Suiza y Dinamarca lo hacen en su Código Penal. Ahora bien, independientemente de cuál fuera la estrategia legislativa adoptada por los países europeos, todas estas reformas se encaminaron a incorporar el nuevo paradigma que considera al privado de libertad como un sujeto de derechos que debe ser protegido e incentivado en la inserción social, y a contemplar mecanismos judiciales que revisen las decisiones adoptadas por la administración penitenciaria que signifiquen vulneración de derechos (Kaiser \& Schöch, 2002, pp. 90-112).

9 En 2006, el BVerfG (fallo 116, 69), siguiendo las Recomendaciones del Consejo de Europa para la ejecución de medidas ambulatorias y sanciones privativa de libertad, reafirma la especialidad en la etapa de ejecución de la sanción penal juvenil y la necesidad de que su regulación esté definida por el legislador. La ejecución tendría un componente educativo reforzado, las oferta tanto pedagógica como terapéutica tendría que ser garantizada en todas las etapas de la ejecución, desde el ingreso hasta la puesta en libertad, y las normas soft law serían vinculantes para el Estado (Landau, 2011, p. 135). 
de la pena de prisión y medidas de seguridad de 1976 mantiene vigente su capítulo decimocuarto referente a los recursos jurídicos, quedando el tema de control judicial, tramitación, plazos y competencia de los tribunales de ejecución de la pena dentro de la esfera federal, sin poder ser reformado por las normativas estaduales (Laubenthal, 2015, p. 567). Igualmente, la Ley Federal de 1976, de acuerdo con el artículo 125 a) inciso 1 de la GG, se mantuvo vigente y vinculante para los estados federados que no dictaban una ley de rango estadual de ejecución de la pena de prisión de adultos. Esta cláusula fue de gran relevancia debido a que la expedición de leyes de ejecución de la pena de prisión fue progresiva en Alemania. A este respecto, véase la siguiente tabla:

Tabla 1

Fecha de expedición de las leyes de ejecución de la pena de prisión en los Estados Federales

\begin{tabular}{|l|c|}
\multicolumn{1}{c|}{ Estados federados } & Fecha de expedición de la ley \\
\hline Baviera & $10 / 12 / 2007$ \\
Hamburgo & $14 / 07 / 2009$ \\
Baden-Wurtemberg & $10 / 11 / 2009$ \\
Hesse & $28 / 06 / 2010$ \\
Sarre & $24 / 04 / 2013$ \\
Sajonia & $16 / 05 / 2013$ \\
Mecklemburgo Pomerania Occidental & $07 / 05 / 2013$ \\
Turingia & $27 / 02 / 2014$ \\
Renania-Palatinado & $08 / 05 / 2013$ \\
Baja Sajonia & $08 / 04 / 2014$ \\
Brandeburgo & $24 / 04 / 2014$ \\
Bremen & $25 / 11 / 2014$ \\
Renania del Norte-Westfalia & $13 / 01 / 2015$ \\
Sajonia-Anhalt & $18 / 12 / 2015$ \\
Berlín & $16 / 04 / 2016$ \\
Schleswig-Holstein & $09 / 01 / 2017$
\end{tabular}

EJECUCIÓN DE LA

PENA DE PRISIÓN

DE ADULTOS EN

ALEMANIA: ANÁLISIS

DE LAS LEYES

ESTADUALES A

LA LUZ DE LA LEY

FEDERAL DE 1976 Y

LA JURISPRUDENCIA

DEL TRIBUNAL

CONSTITUCIONAL

FEDERAL ALEMÁN

(BVERFG)*

ADULT PRISON

LAW IN GERMANY:

ANALYSIS OF STATE

LAWS IN THE LIGHT

OF THE FEDERAL

LAW OF 1976 AND

GERMAN FEDERAL

CONSTITUTIONAL

COURT'S (BVERFG)

CASE LAW

Fuente: Dünkel, Pruin, Beresnatzki y Treig (2018, p. 25).

En el plano estadual, cada uno de los estados cuenta con leyes de ejecución de la pena de prisión de adultos que regulan todos los temas vinculados con los «fines, principios, trabajo, medidas disciplinarias, medidas de seguridad, salidas, trabajo, uso de la fuerza, etcétera», quedando únicamente fuera del ámbito de regulación lo relativo al control judicial que se encuentra normado a nivel federal (Neubacher, 2015a, p. 5). Esta normativa mixta tiene por destinatarios a los adultos 
«hombres y mujeres civiles» que son condenados a la pena de prisión bajo el estatuto del Código Penal. A los soldados, por su parte, debe aplicárseles la ordenanza de ejecución del ejército federal. En el caso de los adolescentes infractores, se les aplica la Ley de Tribunales Juveniles, y para el caso de la pena de prisión juvenil, la ley estadual general sobre ejecución de la pena de prisión o la ley estadual de ejecución de la pena de prisión especial para adolescentes, según sea el caso (Dünkel et al., 2018, pp. 31-32; Ostendorf \& Drenkhahn, 2017, p. 259).

Las estrategias legislativas que adoptaron los Länder fueron distintas y resulta interesante mencionar cómo se han desarrollado los procesos legislativos. A modo de ejemplo, hay estados federados que han decidido diseñar su ley de ejecución de forma individual, como BadenWurtemberg, Baviera, Brandeburgo y Baja Sajonia. Otros estados, en cambio, han decidido diseñar conjuntamente un proyecto de ley o «Musterentwurf zum Landesstrafvollzugsgesetz», como es el caso de Berlín, Bremen, Mecklemburgo Pomerania Occidental, RenaniaPalatinado, Schleswig-Holstein, Thuringia y Sarre (Dünkel et al., 2018, p. 25).

Otra de las estrategias legislativas emprendidas por los estados federados consistió en regular en un solo cuerpo normativo (Kombi-Gesetz) el tema de la ejecución de la pena de prisión de adultos y adolescentes, este es el caso, de Baviera, Baja Sajonia y Baden-Wurtemberg (Dünkel et al, 2018, p. 29; Ostendorf \& Drenkhahn, 2017, p. 259). La doctrina no ha dudado en criticar esta estrategia legislativa por entender que la regulación de la ejecución de la pena de prisión juvenil dentro de la ley de adultos debilitaría el principio de especialidad que debe regir todas las dimensiones del sistema penal juvenil. El establecimiento de reglas y procesos iguales para todos los centros, sean de adultos o adolescentes, no permitiría recoger de forma adecuada las particularidades de la adolescencia (Walter \& Kirchner, 2012, p. 709). Los estados federados de Berlín, Bremen, Hamburgo, Hesse, Mecklemburgo Pomerania Occidental, Sarre, Sajonia, Schleswig-Holstein y Renania-Palatinado siguieron la estrategia legislativa de normar en leyes distintas los temas de la ejecución de la pena de prisión de adultos y adolescentes (Ostendorf \& Drenkhahn, 2017, p. 259).

\section{REGULACIÓN DE LAS LEYES ESTADUALES A LA LUZ DE LA LEY FEDERAL DE 1976 Y LA JURISPRUDENCIA DEL BVERFG \\ III.1. Estatus jurídico del privado de libertad}

El paradigma del preso como sujeto de derechos y una administración penitenciaria obligada a custodiar y proteger al privado de libertad fue asentado en la década del setenta por el BVerfG y cristalizado luego por 
la Ley Federal de 1976. Esta última se encargó de plasmar una serie de principios que reconocían la necesaria protección del preso dentro de la esfera del encierro (Neubacher, 2015a, pp. 12-13) ${ }^{10}$.

El BVerfG, utilizando la dignidad humana y el principio de un Estado social ${ }^{11}$ como fundamento, ha dictaminado - en materia de reconocimiento de derechos de los privados de libertad - que la cárcel no puede significar la muerte civil de los prisioneros, que los condenados tienen derechos y obligaciones, y que el Estado tendría - dentro de esta dimensión del sistema penal - la tarea de custodia y protección de los reclusos (Landau, 2011, p. 132). Adicionalmente, el BVerfG reflexiona en torno a las implicancias de la actividad penitenciaria y cómo en su ejercicio se puede limitar derechos fundamentales de los prisioneros. Estas restricciones exigirían, sobre la base del principio de legalidad, una regulación dada por el legislador. En concreto, «los derechos fundamentales de los presos solo pueden restringirse a través de una ley y la limitación de dichos derechos solo puede ser considerada cuando es indispensable para el logro de los fines de la sociedad, contemplados por el orden de valores de la GG» ${ }^{12}$ (Sentencia 33,1; Landau, 2011, pp. 130-131).

Asimismo, la Ley Federal de 1976, al reconocer al preso como un sujeto de derecho (artículo 4, §2), se preocupa de que los efectos negativos propios del encierro y los eventuales abusos sean contenidos por la administración penitenciaria (Kaiser \& Schöch, 2003, p. 42). En esa lógica, la ley contempla los principios de equiparación, integración, prevención de los riesgos inherentes a la ejecución de la prisión, diferenciación y separación. De acuerdo con estos principios, el régimen

10 Es un hecho reconocido por la evidencia que el encierro genera en el ser humano una serie de problemas psicológicos, psiquiátricos y psicosomáticos. Adicionalmente, dentro de la cárcel se producen altos niveles de violencia que ponen en riesgo la vida e integridad del sujeto que cumple condena. Factores que contribuirían a la desculturalización y deshumanización de los presos. Para más información, véase Callies y Müller-Dietz (2002, p. 5).

11 La dignidad humana y el principio de Estado social han sido claves para orientar las decisiones del BVerfG en esta materia. La dignidad humana se desprende de la capacidad del ser humano de realizarse como tal en la medida de sus posibilidades. El Estado no solo debe observar de manera neutral este desarrollo individual, absteniéndose de todo enjuiciamiento o discriminación -incluso en los casos en que dicha realización sea vana o parezca peligrosa para la comunidad-, sino que debe colaborar para que todos los individuos puedan superar sus imperfecciones e insuficiencias, sobre todo para aquellos que han caído en desgracia, por ejemplo, los que cometen delitos y son condenados a la pena de prisión (Benda, 2001a, pp. 124-125). El Estado social como principio rector vinculante para los poderes públicos obliga al Estado, en el decir de Benda, no solo a establecer las condiciones básicas para que la vida se despliegue sin violencia, además lo obliga a brindar asistencia estatal básica, ya que los talentos personales y destrezas particulares de los ciudadanos pueden no ser suficientes, por lo que estos requerirían de apoyo estatal (2001b, pp. 521-528).

12 El más conocido de los fallos del BVerfG en materia de presos adultos es el de 1972, el cual obliga al Estado a emprender la reforma que se cristaliza en la Ley Federal de 1976 (Sentencia 33, 1). EI BVerfG cuestiona la lógica de la relación de sujeción especial, paradigma que considera al preso como súbdito del Estado y solo portador de obligaciones. De acuerdo con lo anterior, el BVerfG ordena al Estado alemán a reformar el sistema de ejecución de la sanción privativa de libertad de los adultos, en concreto, poner término a la regulación reglamentaria, cambiar el paradigma en torno al estatus de los prisioneros, considerarlos sujetos de derechos, y dictar una ley federal que regule el tema. Para todo lo anterior, el tribunal fija un plazo de cinco años (Landau, 2011, p. 132; Kaiser \& Schöch, 2003, pp. 29-30). 
penitenciario debe adaptarse en lo posible a las condiciones generales de vida (artículo 3.1: equiparación); debe contrarrestar las consecuencias nocivas del encierro (artículo 3.2: prevención de riesgos); debe organizarse de forma tal que ayude al interno a integrarse en libertad (artículo 3.3: integración); debe garantizar un tratamiento acorde con las diferentes necesidades del recluso (artículo 141: diferenciación); y debe separar a las mujeres, adolescentes e imputados de los adultos hombres condenados (artículos 140, 142, 176: separación) (Kaiser \& Schöch, 2003, p. 133). Adicionalmente, la Ley Federal de 1976, en su título octavo, contemplaba una cláusula donde se establecen los derechos fundamentales que la administración penitenciaria podría limitar en su ejercicio. Estos eran, según el artículo 196, la integridad corporal y libertad personal; y el secreto epistolar y de las comunicaciones (Kaiser \& Schöch, 2003, p. 31).

En la gran mayoría de las legislaciones estaduales se reconoce que la relación del Estado con los condenados se encuentra sujeta a los términos contemplados en la GG (Laubenthal, 2015, p. 23). Se considera que los privados de libertad gozan de los derechos contemplados en los artículos 19 a 104 de la GG (Neubacher, 2015a, p. 12; Laubenthal, 2015, p. 23; Kaiser \& Schöch, 2003, p. 28) ${ }^{13}$. Se contempla, por ejemplo, en Baden-Wurtemberg (artículo 1), Baviera (artículo 2), Brandeburgo (artículo 2), Hamburgo (artículo 2), Hesse (artículo 2), Mecklemburgo Pomerania Occidental (artículo 2), Baja Sajonia (artículo 5), Sarre (artículo 2), Sajonia (artículo 2), Schleswig-Holstein (artículo 4.1), y Turingia (artículo 2) que la actividad penitenciaria debe realizarse dentro de las bases de un Estado de Derecho, social y democrático. En Baden-Wurtemberg (artículo 2.1) se alude al principio de la dignidad humana en la actividad penitenciaria y se prohíbe todo tipo de medida o trato en el interior de las prisiones que sea inhumano o degradante. Adicionalmente las legislaciones incorporan los principios de la Ley Federal de 1976 de equiparación, integración y prevención de los riesgos inherentes en la ejecución, por ejemplo, artículo 2 \$§2-3 en Baden-Wurtemberg, artículo 5 §§1-2 en Baviera, artículo $7 \S \S 1-2$ en Brandeburgo, artículo 3 §1en Hamburgo, artículo 3 en Hesse, artículo 3 en Mecklemburgo Pomerania Occidental, artículo 2 en Baja Sajonia, artículo 7 en Renania-Palatinado, artículo $3 \$ 4$ en Sarre, artículo $3 \S 4$ en Sajonia, y artículo 7 en Turingia.

Las legislaciones también contemplan normas expresas referentes a la limitación de los derechos fundamentales, e indican cuáles serían en

13 A modo de ejemplo, los derechos fundamentales reconocidos en la GG son los siguientes: dignidad humana (artículo 1, §1), derecho a la vida (artículo 2, §2), integridad corporal (artículo 2, §2), igualdad de trato (artículo 3), conciencia (artículo 4), asociación (artículo 9), propiedad (artículo 14), privacidad (artículo 13), petición (artículo 17), derecho a voto (artículo 38), acceso a tribunales (artículos 101, 103), protección a la libertad (artículo 104) (para más información, véase Kaiser \& Schöch, 2003, p. 33). 
concreto los derechos que pueden ser restringidos (Neubacher, 2015b, p. 82; Laubenthal, 2015, p. 23). Por ejemplo, en la ley de Mecklemburgo Pomerania Occidental se establece que en la ejecución de la pena de prisión solo pueden restringirse los derechos de la integridad corporal, libertad personal, secreto epistolar y las comunicaciones. Similares normas que siguen la fórmula de la Ley Federal de 1976 se encuentran en la ley de Baden-Wurtemberg (artículo 57), de Baviera (artículo 207), de Brandeburgo (artículo 141), de Hamburgo (artículo 129), de Hesse (artículo 82), de Baja Sajonia (artículo 202), de Sarre (artículo 117), de Sajonia (artículo 119), de Berlín (artículo 116), de Schleswig-Holstein (artículo 147) y de Turingia (artículo 141).

El principio de separación según el género es reconocido exigiendo que las mujeres cumplan condena en centros de cumplimiento femenino o al menos en una sección especial dentro de un recinto de hombres. Esta separación se funda en la protección de la intimidad y en la evitación de abusos sexuales. Este principio se contempla en todas las legislaciones estatales (Baden-Wurtemberg, artículo 4, inciso 1; Baviera, artículo 166, inciso 2; Brandeburgo, artículo 17, inciso 1; Hamburgo, artículo 98; Hesse, artículo 70, inciso 2; Mecklemburgo Pomerania Occidental, artículo 10; Baja Sajonia, artículo 172, inciso 1; Sajonia, artículo 10; Berlín, artículo 11; Schleswig-Holstein, artículo 10.1; y Turingia, artículo 17). Laubenthal, pese a la consagración del principio de separación, ha criticado que las legislaciones no profundizan en las necesidades que dichas secciones especiales deberían satisfacer mínimamente, atendiendo a las características del grupo que se encuentra encerrado (2015, p. 501).

Las leyes también contemplan excepciones donde los hombres y mujeres pueden participar de actividades mixtas o comunes, entre ellas, clases, terapias grupales, capacitaciones y trabajo. En estos casos, se exige que el legislador regule las actividades conjuntas. Esta excepción ya se encontraba contemplada en la Ley Federal de 1976 que permitía prescindir de la sección separada para posibilitar la participación del recluso en medidas de tratamiento en otra sección (Böhm, 2005, p. 864; Kaiser \& Schöch, 2003, p. 290; véase, en el mismo sentido, los siguientes ejemplos: artículo $4 \$ 6$ Baden-Wurtemberg, artículo 166 $\S 3$ Baviera, artículo 17 \$5 Brandeburgo, artículo 98 \$4 Hamburgo, artículo 10 Mecklemburgo Pomerania Occidental, artículo $172 \S 1$ Baja Sajonia, artículo $17 \S 5$ Turingia, artículo 11 Berlín, y artículo 10.2 Schleswig-Holstein). En lo relativo a la separación entre condenados e imputados, el principio de inocencia contemplado en el artículo 6 de la Convención Europea de Derechos Humanos exige el encierro de imputados en centros distintos de los condenados. En la práctica, en los Länder los imputados terminan cumpliendo la medida cautelar en un 
centro de condenados, pero en una sección especial destinada para ellos (Laubenthal, 2015, pp. 39-40).

Otro de los principios contemplados en la Ley Federal de 1976 que ha sido considerado en las legislaciones estaduales es el de la diferenciación. El principio contemplado en el artículo 141 de la mencionada ley exige establecimientos o secciones especiales que den cabida a las distintas necesidades de tratamiento que presentan los internos. Por ejemplo, debe contarse con personal capacitado para un determinado grupo de condenados, distintos niveles de seguridad, diferentes grados de aplicación de permisos o salidas, variadas ofertas programáticas, distintos espacios y tamaños para las actividades requeridas para el tratamiento (Laubenthal, 2015, pp. 41-42; Wirth, 2005). Al igual que en las secciones femeninas, las regulaciones han sido en extremo sucintas a la hora de especificar en qué consistiría la diferenciación de los espacios (véase, por ejemplo, Baden-Wurtemberg, artículo 4 inciso 1; Baviera, artículo 167; Brandeburgo, artículos 7 y 107; Hamburgo, artículo 99; Hesse, artículo 72; Mecklemburgo Pomerania Occidental, artículo 3 inciso 7 y artículo 93 inciso 1; Baja Sajonia, artículo 173; Sajonia, artículo 3 inciso 7 y artículo 93; Berlín, artículo 101.3; Schleswig-Holstein, artículo 127; y Turingia, artículos 7 y 105).

\section{III.2. Control judicial}

Estrechamente vinculado con el estatus del preso se encuentra el control judicial dentro de las prisiones. En materia de control judicial, la influencia de la Ley Federal de 1976 en las leyes estaduales de ejecución de la pena de prisión de adultos es obligatoria. Como se mencionó, de acuerdo con la GG, la sección de la Ley Federal relativa al control judicial, Título Decimocuarto, Recursos jurídicos, continúa vigente y es aplicable a todas las legislaciones estaduales (Bachmann, 2015, pp. 1340-1341).

La solicitud de resolución judicial (Antrag auf gerichtliche Entscheidung) de la Sala de Ejecución Penitenciaria se encuentra regulada en el artículo 109 de la Ley Federal de 1976. De acuerdo con dicho artículo, con la solicitud se podrá demandar la decisión sobre una medida rechazada u omitida. La pretensión solo es admisible «cuando el recurrente justifica que, con la medida, rechazo u omisión, ha sido lesionado en sus derechos». La solicitud solo podrá presentarse una vez agotada la vía administrativa (Bachmann, 2015, pp. 1344-1356; Kaiser \& Schöch, 2002, pp. 361-362).

En torno al plazo o Antragfsrist, la solicitud deberá ser presentada en el «plazo de dos semanas después de la comunicación o notificación escrita de la medida o de su rechazo. Si el solicitante no pudo observar 
el plazo por causas que no le son imputables, se le concederá, a petición suya, la reposición de las actuaciones al estado anterior» (Bachmann, 2015, pp. 1344-1356; Kaiser \& Schöch, 2002, p. 361). Si la medida es considerada antijurídica y representa una violación de los derechos del solicitante, el juzgado revocará la medida en su resolución judicial (gerichtliche Entscheidung) (Bachmann, 2015, pp. 1344-1356; Kaiser \& Schöch, 2002, pp. 361-362). En caso de que la medida haya sido ejecutada, «el juzgado podrá declarar de qué manera la autoridad penitenciaria revocará con efecto retroactivo la ejecución» (Bachmann, 2015, pp. 1344-1356; Kaiser \& Schöch, 2002, pp. 361-362).

\section{III.3 Fin de la ejecución de la pena de prisión}

La Ley Federal de 1976 incorporó el principio de resocialización como eje rector. El concepto de resocialización había sido adoptado por la comisión especial encargada de la redacción de una nueva legislación penitenciaria de 1967 (Kaiser \& Schöch, 2003, pp. 113-114). Dicha comisión especial tomó distancia del contexto comparado que se alejaba del concepto resocializador, en particular, de los Estados Unidos y Escandinavia, donde existían serias dudas sobre el modelo preventivo especial positivo (Zysman Quirós, 2013, p. 231) ${ }^{14}$.

Alemania occidental dirigió su Ley Federal de 1976 específicamente a la prevención especial positiva ${ }^{15}$. El artículo 2 de la misma ley declaraba que la reintegración del prisionero a la sociedad era el único objetivo de la ejecución de la sentencia (Neubacher, 2015b, p. 37; Böhm, 2005, pp. 68-69; Kaiser \& Schöch, 2003, pp. 113-114; Dünkel \& Rössner, 2001, pp. 300-302). Con la decisión adoptada por el legislador, la prevención general o la retribución no tenían protagonismo en la etapa de ejecución de la sentencia. De acuerdo con la denominada «teoría de los tres pilares», la prevención y retribución general se logran mediante la amenaza abstracta del castigo y con la determinación judicial de la sentencia, mientras que la ejecución de la pena de prisión se centra únicamente en la prevención especial positiva (Böhm, 2005, pp. 68-69; Kaiser \& Schöch, 2003, p. 115; Dünkel \& Rössner, 2001, p. 302; Roxin, 1997, p. 41).

Igualmente, la doctrina informa que la Ley Federal de 1976 no pudo eliminar la tensión de larga data —que había sido inherente a los hitos normativos anteriores - entre el ideal de «seguridad y orden» y el de «tratamiento y resocialización». Dicha tensión se salvó con la distinción

\footnotetext{
14 En la época había críticas a las penas indeterminadas, así como a los experimentos reñidos con la ética que se realizaron sobre algunos privados de libertad, por ejemplo, castración química y pruebas de medicamento. También surgieron dudas con respecto a la efectividad de la reinserción (véase Zysman Quirós, 2013, pp. 254-266).

15 Esta decisión también fue adoptada posteriormente por otras legislaciones en Europa como la española de 1979 (véase Juanatey Dorado, 2016, pp. 86-88).
}

EJECUCIÓN DE LA PENA DE PRISIÓN DE ADULTOS EN ALEMANIA: ANÁLISIS DE LAS LEYES

ESTADUALES A

LA LUZ DE LA LEY FEDERAL DE 1976 Y LA JURISPRUDENCIA DEL TRIBUNAL

CONSTITUCIONAL FEDERAL ALEMÁN (BVERFG)*

ADULT PRISON LAW IN GERMANY: ANALYSIS OF STATE LAWS IN THE LIGHT OFTHE FEDERAL LAW OF 1976 AND GERMAN FEDERAL CONSTITUTIONAL COURT'S (BVERFG) CASE LAW 
del legislador federal entre fines y tareas (artículo 2 de la Ley Federal de 1976) que buscar armonizar los dos intereses, considerando como tarea de la ejecución la protección general de la comunidad, y como fin de la ejecución, la prevención especial positiva (Cornel, 2009, p. 303; Böhm, 2005, pp. 68-69; Kaiser \& Schöch, 2003, pp. 119-123; Dünkel \& Rössner, 2001, p. 302; Walter, 1999, pp. 88-95; Roxin, 1997, p. 41). No cabe duda de que el objetivo establecido para el encarcelamiento en la Ley Federal de 1976 es el de la resocialización y que excluye otros fines del castigo como la incapacitación, retribución o prevención general (Böhm, 2005, pp. 68-69; Kaiser \& Schöch, 2003, p. 123; Walter, 1999, p. 86; Laubenthal, 1998, p. 52). En este sentido, el artículo 2, inciso segundo de la Ley Federal de 1976 fue claro al establecer que la protección de la colectividad frente a posibles delitos futuros cede ante el objetivo de la resocialización.

En el fallo Lebach (Sentencia 35), el BVerfG se abocó a la finalidad del sistema penitenciario. Al privado de libertad como portador de la dignidad humana se le debe garantizar la resocialización y, para ello, se ordena a la institución penitenciaria contemplar una amplia oferta programática que permita al condenado prepararse para su regreso a la comunidad y llevar a cabo con posterioridad a la ejecución de la pena una vida libre de delitos. Asimismo, el fallo establece que la ejecución de la sanción privativa de libertad debe entenderse como un proceso cuyas etapas deben tener como finalidad la reinserción social del prisionero. Desde esta perspectiva, el principio de continuidad exigiría que toda dimensión de la ejecución - desde el ingreso hasta la puesta en libertad, incluso el necesario proceso de acompañamiento posterior- debe girar en torno a la reinserción social del condenado. La vulnerabilidad del privado de libertad, la necesaria oportunidad que un Estado social debe brindar a sus ciudadanos desventajados, entre ellos los condenados, exige al Estado, y en particular a la institución penitenciaria, desarrollar un concepto efectivo de reinserción. El BVerfG vinculó los conceptos de reinserción social y prevención del delito, contemplando que una de las mejores estrategias que debería adoptar el Estado en la lucha contra el delito es una efectiva reinserción social (Landau, 2011, p. 132).

Bajo la reforma de 2006, el panorama de las leyes de ejecución de la pena de prisión en materia de fines de la ejecución quedó dividido. No existe unanimidad en las leyes de ejecución estaduales en torno a cuál es el interés más importante (Cornel, 2018, p. 19; Neubacher, 2015b, pp. 32-33; Laubenthal, 2015, p. 103). Existe un grupo de legislaciones (Baden-Wurtemberg, artículo 1; Brandeburgo, artículo 2; Hamburgo, artículo 2; Mecklemburgo Pomerania Occidental, artículo 2; RenaniaPalatinado, artículo 2; Sarre, artículo 2; Berlín, artículo 2; SchleswigHolstein, artículo 2 y Sajonia, artículo 2) que acoge como principio rector el de la resocialización, contemplando la misma fórmula legal 
de la Ley Federal de 1976. En estas legislaciones, la protección de la colectividad frente a eventuales hechos punibles cede ante el objetivo de la resocialización y es planteada como una tarea de la ejecución de la pena de prisión.

Con todo, las legislaciones mencionadas en el párrafo anterior incorporan un nuevo elemento a la finalidad que considera los intereses de la víctima. Estiman relevante que la administración no solo ayude al interno a integrarse a la vida en libertad, sino que además lo ayude a hacerse responsable por el hecho cometido y los daños ocasionados a la víctima. En cambio, las legislaciones de Baviera, Hesse y Baja Sajonia contemplan la pluralidad de fines, y le otorgan a la protección de la colectividad ante futuros hechos punibles la misma jerarquía que a la reinserción. Dichas finalidades deberán ser ponderadas durante la ejecución de la pena de prisión. Este nuevo criterio presentaría, según Neubacher, serias dudas de constitucionalidad, iría contra el claro estándar jurisprudencial del BVerfG en la materia y generaría serios problemas de igual aplicación de la norma penitenciaria dentro de Alemania (2015b, pp. 40-41).

\section{III.4. Salidas o flexibilización de la prisión}

La flexibilización de la prisión es un valioso medio que favorece la resocialización del preso, permite que el funcionamiento del centro de ejecución se asimile a una institución pública normal y atenúa los daños que el encierro genera sobre el privado de libertad (Kaiser \& Schöch, 2002, p. 265). De acuerdo con Laubenthal las salidas sirven al tratamiento y resocialización y se vinculan con aquellas actividades como el trabajo, educación, terapia y otras actividades de corte ocupacional que se realizan fuera del recinto carcelario (2015, p. 346). Si bien todas las legislaciones estaduales contemplan la posibilidad de salidas periódicas del recinto por motivos de trabajo, motivos importantes o por tener lugar una audiencia judicial que requiere la presencia del condenado, existen a propósito de los requisitos para acceder a ellas marcadas diferencia con la Ley Federal de 1976.

Las salidas fueron instauradas por primera vez a finales de los años sesenta como experimentos que buscaban potenciar el trabajo fuera del establecimiento carcelario. La Ley Federal de 1976 las contempló con el objetivo de trabajar o cumplir con diligencias a determinadas horas del día (Kaiser \& Schöch, 2002, pp. 48-51). En términos generales, para acceder a estas salidas era necesario, bajo la Ley Federal de 1976, que el «privado de libertad haya cumplido en reclusión por lo menos seis meses de la ejecución y que no existiera peligro de que este rehúya la ejecución de la condena o abuse de los beneficios en la ejecución para delinquir» (artículo 11, numerales 1 y 2). Al año, cada privado de libertad tenía

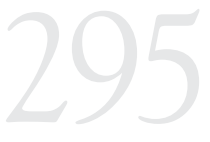

EJECUCIÓN DE LA PENA DE PRISIÓN DE ADULTOS EN ALEMANIA: ANÁLISIS DE LAS LEYES

ESTADUALES A

LA LUZ DE LA LEY FEDERAL DE 1976 Y LA JURISPRUDENCIA DEL TRIBUNAL CONSTITUCIONAL FEDERAL ALEMÁN (BVERFG)*

ADULT PRISON LAW IN GERMANY: ANALYSIS OF STATE LAWS IN THE LIGHT OF THE FEDERAL LAW OF 1976 AND GERMAN FEDERAL CONSTITUTIONAL COURT'S (BVERFG) CASE LAW 
un máximo de 21 días calendarios para salir de la cárcel (artículo 13) (Kaiser \& Schöch, 2002, pp. 147-151).

En el caso de la cadena perpetua, la Ley Federal de 1976 contemplaba que el condenado podía obtener un permiso de salida, si este había estado recluido durante diez años. Es importante precisar que el fallo 45, 187 del BVerfG consideró que la imposición de la cadena perpetua debería dejar abierta al condenado, una vez cumplida una parte considerable de la condena, al menos la posibilidad de libertad por la vía de la libertad condicional. La pena perpetua sin flexibilidad supone que el Estado se sustraiga de su obligación de resocializar al delincuente. De la dignidad humana y el principio del Estado social se desprende la obligación del Estado de garantizar un mínimo de existencia. Con una dignidad entendida en estas condiciones, el Estado no podría privar de libertad a los seres humanos sin darles la posibilidad de poder obtenerla nuevamente (Landau, 2011, pp. 133-134). El fallo obligó al legislador a considerar la aplicación de la puesta en libertad anticipada para la cadena perpetua y a emprender en 1982 una reforma que terminó por contenerse en el artículo 57a del Código Penal (StGB) (Dünkel, 2013b, p. 2139).

En las legislaciones estaduales es preciso observar dos tendencias en esta temática. Una sigue la fórmula de la Ley Federal de 1976, la otra establece nuevos criterios. En este último grupo nos encontramos, por ejemplo, con Baden-Wurtemberg y Baja Sajonia que incorporan la prevención especial positiva como razón que podría justificar la denegación de la salida (Dünkel et al., 2018, pp. 26-27).

En Baviera también se contemplan criterios diferentes en materia de cadena perpetua y para los casos de condenados a pena de prisión por delitos violentos y sexuales. En el primer caso, el mínimo tiempo de ejecución transcurrido dentro de la prisión para acceder a las salidas es de 12 años en vez de 10 como en la Ley Federal. En el caso de los condenados por delitos violentos y sexuales, se permite considerar, en la decisión en torno a la concesión de las salidas, los informes y opiniones vertidos en la etapa de investigación y durante el proceso penal. Asimismo, se establece que la concesión de las salidas debe estar fundada en pruebas o antecedentes especiales. Para los condenados por delitos sexuales se considerará, además, informes psicológicos y psiquiátricos (Dünkel et al., 2018, pp. 26-27).

En Hesse se establece, para el caso de los condenados por delitos sexuales y violentos, el requisito de fundados antecedentes que no dan lugar a una fuga o quebrantamiento. Además, se exige más de cinco años de cumplimiento efectivo de la sanción privativa de libertad para acceder a las salidas (artículo 13.5.1) (Dünkel et al., 2018, pp. 26-27). Adicionalmente, es posible advertir diferencias en el número total de 
días al año que un privado de libertad tendría para salir. En Hamburgo y Renania del Norte-Westfalia se aumenta el plazo a 24 días anuales, en Schleswig-Holstein se contemplan 30 días anuales. Otros Estados han innovado y no contemplan límites de días, este es el caso de Berlín, Brandeburgo, Bremen, Mecklemburgo Pomerania Occidental, RenaniaPalatinado, Sarre y Sajonia (Dünkel et al., 2018, pp. 26-27).

\section{III.5. Contacto con el mundo exterior}

Las leyes de ejecución estaduales consideran, al igual que la Ley Federal de 1976, que el interno se contacta con la comunidad a través de las visitas, correspondencia escrita, telecomunicaciones, recepción de paquetes o encomiendas y salidas (Kaiser \& Schöch, 2003, p. 170). En las legislaciones estaduales, el contacto con el mundo exterior es un derecho que, bajo determinadas circunstancias, puede ser limitado por la ley (Laubenthal, 2015, pp. 208-209). También se contempla, en la mayoría de las legislaciones, al igual que en la Ley Federal de 1976, que deberá fomentarse la vinculación del interno con personas del exterior que ejerzan una positiva influencia en él (considérese, entre otros, Baden-Wurtemberg, artículo 19.1; Baviera, artículo 26; Brandeburgo, artículo 33; Hamburgo, artículo 26; Hesse, artículo 33; Mecklemburgo Pomerania Occidental, artículo 25; Renania-Palatinado, artículo 32; Sarre, artículo 25; Sajonia, artículo 25).

\section{III.6. Tratamiento y su contenido}

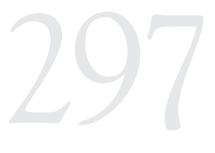

EJECUCIÓN DE LA PENA DE PRISIÓN DE ADULTOS EN ALEMANIA: ANÁLISIS DE LAS LEYES

ESTADUALES A

LA LUZ DE LA LEY FEDERAL DE 1976 Y LA JURISPRUDENCIA DEL TRIBUNAL CONSTITUCIONAL FEDERAL ALEMÁN (BVERFG)*

ADULT PRISON LAW IN GERMANY: ANALYSIS OF STATE LAWS IN THE LIGHT OF THE FEDERAL LAW OF 1976 AND GERMAN FEDERAL CONSTITUTIONAL COURT'S (BVERFG) CASE LAW

En la Ley Federal de 1976 no existió una definición de tratamiento. El legislador de la época no quiso cerrarse a determinados métodos científicos, ya que los campos de la educación, la psicología y la medicina están constantemente sujetos a mayor desarrollo. Hoy en día no solo las medidas terapéuticas en sentido estricto están comprendidas en el ámbito del tratamiento, sino que además este incluye otras actividades penitenciarias como la formación profesional, el trabajo, las actividades recreativas y los permisos penitenciarios (Walter, 1999, p. 299; Cornel, 2009, pp. 50-51).

En las legislaciones estaduales se menciona en varias ocasiones el concepto de tratamiento, por ejemplo, en Baden-Wurtemberg, en el artículo 3 inciso 1; en Baviera, en el artículo 6 inciso 1; y en Hamburgo, en el artículo 5 inciso 1 . Sin embargo, son pocas las legislaciones que contienen una definición al respecto, de modo que la mayoría de las legislaciones adopta el criterio de la Ley Federal de 1976 que guarda silencio al respecto por las razones ya mencionadas. Con todo, Baviera y Hamburgo destacan por avanzar en una definición. Según el artículo 4 de la ley de Hamburgo, tratamiento significa todas aquellas medidas y ofertas de programas terapéuticos que permiten al condenado, 
por una parte, reintegrarse a la sociedad con una vida en responsabilidad social y sin delito y, por otra, fortalecer sus capacidades. A su turno, el artículo 3 de la ley de Baviera considera como tratamiento todas aquellas medidas que permiten al condenado llevar una vida libre de delitos, que están al servicio de la inhibición delictual y protección de las víctimas.

En la gran mayoría de las legislaciones estaduales existe acuerdo que el tratamiento, al igual que lo exigido por la Ley Federal de 1976, incluye medidas escolares, de capacitación, de trabajo, psicológicas y social-pedagógicas. También es un denominador común la utilización del modelo de Bonta y Andrew, donde la intensidad del tratamiento se orienta por el principio de riesgo. El contenido del tratamiento, como su objetivo, se diseña sobre la base de los especiales factores o déficit criminológicos del condenado (principio de necesidad) y las capacidades de aprendizaje como habilidades presentes en el interno (principio de responsividad) (Laubenthal, 2015, p. 412).

En la práctica, el tratamiento se ha orientado hacia dos puntos principales de enfoque. Por un lado, se concentra en la mejora de las perspectivas futuras de los reclusos mediante la formación profesional y la adquisición de competencias. Por otro lado, la terapia busca mejorar la competencia social del delincuente. Frecuentemente, este «entrenamiento social» consiste en un juego de roles en el que se representan problemas cotidianos tales como la liquidación de las deudas, el presupuesto del hogar, el trabajo y las relaciones interpersonales. El tratamiento, según conceptos psicoanalíticos o psicoterapéuticos —que es limitado casi sin excepción a las instituciones socioterapéuticas-, es menos común (Dünkel, 2018, pp. 426-427; Cornel, 2009, pp. 41-42).

\section{II.7. Medidas disciplinarias}

La Ley Federal no contempló un catálogo detallado de obligaciones o conductas. Estas se encuentran diseminadas a lo largo de su cuerpo normativo. El legislador federal solo se refirió en términos generales a la hipótesis de infracción culpable de una obligación como fundamento de la medida disciplinaria (artículo 102, numeral 1) y al principio de responsabilidad que busca despertar en el recluso la importancia de una convivencia ordenada (artículo 81). Adicionalmente, el legislador federal contempló un breve listado de comportamientos obligatorios, tales como someterse al horario cotidiano (artículo 82.1), obedecer órdenes del personal (artículo 82.2), mantener el orden y cuidar los objetos del recinto (artículo 82.3), y dar información sobre peligros para la salud de una persona (artículo 83.4) (Kaiser \& Schöch, 2003, p. 227). Este tipo de cláusulas generales ha sido criticado por la doctrina por no otorgar certeza jurídica al recluso en torno a la conducta que puede o no 
desplegar dentro del recinto (Mika, 2018, p. 67; Dünkel \& Kühl, 2009, p. 84)

En las legislaciones estaduales se reguló en similares términos el principio de responsabilidad (Baden-Wurtemberg, artículo 61 inciso 1 y artículo 62; Baviera, artículo 87 inciso 1 y artículo 88; Brandeburgo, artículo 85 incisos 1 y 3; Mecklemburgo Pomerania Occidental, artículo 73; Renania-Palatinado, artículo 32; Sarre, artículo 25; Sajonia, artículo 74). Las legislaciones estaduales siguieron, además, la técnica legislativa de la Ley Federal y contemplaron catálogos generales de comportamiento. Con esta técnica se desaprovecha la oportunidad de contemplar un claro y preciso catálogo de actuación dentro del recinto que satisfaría las exigencias de tipicidad que se desprenden del principio de legalidad (Mika, 2018, p. 68; Walter, 2015, p. 921). Considérese las legislaciones de Baden-Wurtemberg, Baviera, Hamburgo y Baja Sajonia, las cuales describen las normas de comportamiento de forma diseminada y no en un único catálogo de actuación. Estas normas de comportamiento serían las siguientes (Mika, 2018, p. 67):

- La obligación de usar la ropa entregada por el recinto.

- Entregar objetos recibidos durante las visitas sin autorización.

- Tramitar el envío y recepción de sus cartas a través del establecimiento.

- El recluso debe guardar las cartas recibidas abiertas.

- El recluso está obligado a realizar un trabajo compatible con sus capacidades físicas.

- El interno debe colaborar con las medidas necesarias para la protección sanitaria e higiénica.

- El recluso está sometido al horario cotidiano del establecimiento penitenciario.

- El interno no debe perturbar con su comportamiento la convivencia ordenada.

- El interno debe obedecer las órdenes del personal penitenciario.

- El interno debe informar inmediatamente sobre las circunstancias que puedan significar peligro para la vida o salud de una persona.

- El recluso tiene que mantener en orden y tratar con cuidado su celda, así como los objetos facilitados por el penal.

- El recluso solamente deberá tener o aceptar objetos en su depósito personal que le han sido entregados por la autoridad penitenciaria.

EJECUCIÓN DE LA PENA DE PRISIÓN DE ADULTOS EN

ALEMANIA: ANÁLISIS DE LAS LEYES

ESTADUALES A

LA LUZ DE LA LEY

FEDERAL DE 1976 Y

LA JURISPRUDENCIA

DEL TRIBUNAL

CONSTITUCIONAL

FEDERAL ALEMÁN

(BVERFG)*

ADULT PRISON

LAW IN GERMANY:

ANALYSIS OF STATE

LAWS IN THE LIGHT

OF THE FEDERAL

LAW OF 1976 AND

GERMAN FEDERAL

CONSTITUTIONAL

COURT'S (BVERFG)

CASE LAW 
En el caso de Brandeburgo, Hesse, Mecklemburgo Pomerania Occidental, Renania-Palatinado, Sarre, Sajonia, Berlín, SchleswigHolstein y Turingia se contempla solo una formula general de normas de comportamiento. A saber, las medidas disciplinarias deben ser impuestas cuando el recluso de forma antijurídica y culpable (Mika, 2018, p. 67)

- Lesiona una norma penal o administrativa.

- Introduce objetos en el recinto sin permiso.

- Introduce drogas en el recinto o consume drogas en el recinto.

- Lesiona reiteradamente sus obligaciones dentro del recinto.

Con respecto al proceso para la aplicación de las medidas disciplinarias, la gran mayoría de las leyes estaduales siguieron las reglas de la Ley Federal de 1976. Las medidas disciplinarias son, por lo general, ejecutadas inmediatamente y no se abre un espacio claro para el defensor penitenciario. En la investigación se oirá al recluso; la investigación constará en acta y se incorporarán las evidencias entregadas por el interno. El director comunicará oralmente al recluso la decisión y se entregará una copia de la decisión con una breve referencia a la fundamentación. Asimismo, en los casos en que la medida recaiga sobre una mujer embarazada, madre que amamanta o sobre un interno bajo tratamiento médico, se deberá oír al médico del centro (Mika, 2018, p. 72).

En torno a los tipos de medidas disciplinarias, se admite en las legislaciones estaduales los mismos tipos de medidas contempladas en la Ley Federal de 1976, variando solo la duración. En este sentido, se caracterizan por su dureza las legislaciones de Baviera, Baja Sajonia y Hamburgo. Las medidas disciplinarias consideradas por las legislaciones son las siguientes (Mika, 2018, pp. 69-71):

- Advertencia.

- La restricción o la privación de disposición sobre la privación de disposición sobre la asignación doméstica y la posibilidad para realizar compras.

- Limitación o la privación de las audiciones de radio y televisión.

- Limitaciones o la privación de participación en las actividades de tiempo libre.

- Limitaciones o la privación de participación en actividades laborales o de ocupación.

- Restricción del contacto con personas fuera del penal.

- Arresto. 
Algunas de estas medidas han sido criticadas por la doctrina, por ejemplo, la restricción del contacto con personas fuera del recinto. Razones preventivas especialmente positivas vinculadas con el éxito del tratamiento y la disminución de los efectos negativos que tiene el encierro en la persona del recluso hacen necesario sacar del catálogo de medidas disciplinarias este tipo de restricciones (Mika, 2018, p. 70; Drenkhahn, 2014, p. 363). El arresto también ha sido duramente criticado. El problema es básicamente de índole constitucional y se centra en el artículo 104 inciso 2 de la GG, el cual exige que las decisiones que limiten la libertad deben ser adoptadas por jueces y no por personal de la administración (Mika, 2018, p. 71).

\section{III.8. Medidas de seguridad generales}

Bajo la Ley Federal de 1976 se contemplaron como medidas de seguridad las requisas, registros y el alojamiento de seguridad. Según la Ley Federal, el registro o las requisas podían recaer en la persona del privado de libertad, en su celda y en sus cosas. Para los casos en que la medida recaía en los reclusos, se exigía que debía realizarse por funcionarios hombres y en el caso de las reclusas por funcionarias mujeres. Por último, se permitía el registro corporal con desnudamiento solamente en casos de peligro inminente o por orden del director. Por su parte, el alojamiento de seguridad permitía el traslado del recluso a un establecimiento más apto para su seguridad. De acuerdo con la Ley Federal de 1976, el traslado, procedía en casos de peligro de fuga o en los casos en que el comportamiento del interno presentara un peligro para la seguridad u orden del establecimiento (Kaiser \& Schöch, 2003, p. 223).

Las legislaciones estaduales contemplaron las mismas medidas de seguridad generales contempladas en la Ley Federal (véase, entre otros, Baden-Wurtemberg, artículo 84 inciso1, artículo 62 y artículo 65; Baviera, artículos 91 y 92; Brandeburgo, artículos 86 y 87; Mecklemburgo Pomerania Occidental, artículos 74 y 75; Turingia, artículos 85 y 86; Sarre, artículos 74 y 75; Berlín, artículo 83; y Sajonia, artículos 75 y 76). Con todo, la regulación dada por las legislaciones estaduales a las medidas de seguridad no ha estado exenta de críticas. Mika, por ejemplo, ha criticado la falta de un criterio general de aplicación que exija un elevado peligro de autolesión o para la seguridad u orden del establecimiento. También se ha criticado la falta de plazos de duración máximo que limiten la extensión de las medidas. Si bien en las legislaciones estaduales se contemplan los principios de última ratio, subsidiaridad y proporcionalidad en la aplicación de las medidas de seguridad, nada asegura que en la práctica estos principios sean respetados (Laubenthal, 2015, p. 514; Mika, 2018, p. 66).

EJECUCIÓN DE LA PENA DE PRISIÓN DE ADULTOS EN ALEMANIA: ANÁLISIS DE LAS LEYES

ESTADUALES A

LA LUZ DE LA LEY FEDERAL DE 1976 Y LA JURISPRUDENCIA DEL TRIBUNAL CONSTITUCIONAL FEDERAL ALEMÁN (BVERFG)*

ADULT PRISON LAW IN GERMANY: ANALYSIS OF STATE LAWS IN THE LIGHT OF THE FEDERAL LAW OF 1976 AND GERMAN FEDERAL CONSTITUTIONAL COURT'S (BVERFG) CASE LAW 


\section{III.9. Medidas de seguridad especiales}

Las leyes estaduales innovaron en materia de medidas de seguridad especiales concebidas para proteger a los reclusos de autolesiones o intentos de suicidios, por ejemplo, con el encierro individual en celda para que se tranquilicen (Beruhigungszelle). En este tema, las legislaciones incorporan el control y cuidado a través de observación y monitoreo electrónico al recluso que presenta riesgos de autolesión o suicidio. Se estima que este medio es mucho más efectivo y menos invasivo para el interno que los utilizados bajo la Ley Federal de 1976, por ejemplo, la utilización de fármacos para tranquilizar al preso o el acompañamiento permanente de un funcionario del recinto en su celda (Mika, 2018, p. 65; Witos, Staiger \& Neubacher, 2014, p. 372).

\section{III.10. Tipos de centros y secciones}

Las leyes de ejecución estaduales acogieron, en su gran mayoría, a los tipos de centros o secciones establecidos por la Ley Federal de 1976 (Kaiser \& Schöch, 2003, p. 269). En concreto, se consideran cinco tipos de centros o secciones, a saber: las secciones de ingreso, centros cerrados, centros abiertos, centros de terapia social y las secciones para la puesta en libertad (Laubenthal, 2015, p. 42). Los objetivos que sirven estas secciones son los siguientes:

Las secciones de ingreso están destinadas para el estudio y diseño del tratamiento del interno recién ingresado: realizar estudios de prognosis, clasificación y determinación del recinto o sección donde deberá cumplir la condena de acuerdo con sus necesidades de tratamiento.

Los centros cerrados están concebidos en primera línea para los condenados a penas de larga duración — cinco a más años—y para los que presentan altos niveles de peligrosidad. Estos centros se caracterizan por las estrictas medidas de seguridad y restringida aplicación de beneficios.

Los centros abiertos, por el contrario, se destinan a los internos de bajo nivel de peligrosidad y que no han cumplido los requisitos para que la sanción privativa de libertad se les suspenda, «generalmente no tiene prognosis positiva y la condena a prisión es superior a los dos años». Como es de esperar, en estos centros las medidas de seguridad son relajadas.

Los centros de terapia social se orientan a los internos con necesidades terapéuticas especiales, como abusadores sexuales, drogo dependientes, criminales violentos o personas con imputabilidad disminuida. Dentro de estos centros se desarrollan ofertas especiales de tratamiento con aplicación de medios terapéuticos y ayuda social. 
Las secciones para la puesta en libertad están destinadas para preparar al interno que está pronto a finalizar su condena, entregan apoyo psicológico para controlar los niveles de estrés que significa dejar un recinto cerrado en el cual se ha vivido por años, entregan información sobre las instituciones sociales que fuera de la cárcel brindarán ayuda al egresado y planifican la forma en que deberá subsistir fuera del recinto para que tenga las necesidades básicas cubiertas, por ejemplo, techo y trabajo. Suele ocurrir que en el primer momento de libertad el egresado vive en dependencias aledañas a la cárcel donde habita en departamentos o casas destinadas para los internos puestos en libertad (Laubenthal, 2015, pp. 42-43).

\section{III.11. Trabajo en el interior de prisión}

El BVerfG (Fallo 98, 169) sostuvo que la Constitución obliga al legislador a desarrollar un concepto efectivo de resocialización y que el trabajo penitenciario solo es efectivo en ese sentido si se reconoce apropiadamente. La baja remuneración asignada a los presos es inconstitucional y el legislador tiene que aumentar la remuneración del trabajo penitenciario hasta el punto de que «el preso pueda ser consciente de que el empleo remunerado tiene sentido con el fin de restablecer la base de su vida» (Landau, 2011, p. 133).

Bajo la Ley Federal de 1976, los reclusos están «obligados a ejercer un trabajo compatible con sus capacidades físicas. Se le puede obligar a ejercer trabajos auxiliares hasta un máximo de tres meses al año en el centro penitenciario, y con su consentimiento más allá de dicho plazo» (Kaiser \& Schöch, 2003, p. 181). En el caso de las legislaciones estaduales, dos son las tendencias reconocibles en materia de trabajo dentro de los centros cerrados. Las legislaciones de Baden-Wurtemberg (artículo 47 inciso 1), Baviera (artículo 43), Hamburgo (artículo 38 inciso 1), Hesse (artículo 27 inciso 2), Mecklemburgo Pomerania Occidental (artículo 38), Berlín (artículo 24), Schleswig-Holstein (artículo 29) y Turingia (artículo 29) establecen la obligación de trabajo compatible con las capacidades físicas del interno y con la dignidad humana (Marisken, 2018, p. 52; Laubenthal, 2015, p. 276).

Este criterio, de acuerdo con las Reglas europeas penitenciarias de 2006, no sería contrario a los estándares internacionales en materia de derechos humanos. Las propias reglas se refieren expresamente al punto en los artículos 105. 2 y 105.3. Se podrá «obligar a trabajar a los detenidos o condenados siempre que no hayan alcanzado la edad de la jubilación, y siempre teniendo en cuenta la opinión del médico sobre sus condiciones de salud físicas y mentales. Cuando los detenidos condenados estén obligados a trabajar, sus condiciones laborales se ajustarán a las normas

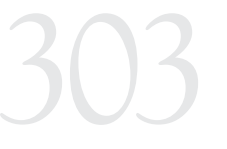

EJECUCIÓN DE LA PENA DE PRISIÓN DE ADULTOS EN

ALEMANIA: ANÁLISIS DE LAS LEYES

ESTADUALES A

LA LUZ DE LA LEY FEDERAL DE 1976 Y LA JURISPRUDENCIA DEL TRIBUNAL CONSTITUCIONAL FEDERAL ALEMÁN (BVERFG)*

ADULT PRISON LAW IN GERMANY: ANALYSIS OF STATE LAWS IN THE LIGHT OF THE FEDERAL LAW OF 1976 AND GERMAN FEDERAL CONSTITUTIONAL COURT'S (BVERFG) CASE LAW 
y controles vigentes en el mundo exterior» (Marisken, 2018, p. 54; Laubenthal, 2015, pp. 276-277).

Las legislaciones de Brandeburgo, Renania-Palatinado, Sarre, Sajonia y Turingia contemplan el trabajo voluntario. Estas legislaciones les dan prioridad a los artículos 26.1, 26.2 y 26.3 de las Reglas penitenciarias europeas de 2006. Según dichos artículos, el trabajo en prisión se considera como un elemento positivo del régimen penitenciario y en ningún caso se impone como castigo. Adicionalmente, las autoridades penitenciarias se esfuerzan en facilitar un trabajo suficiente y útil. Este trabajo permitirá, en la medida de lo posible, mantener o aumentar la capacidad del detenido para ganarse la vida después de salir de la prisión (Marisken, 2018, pp. 52-53; Laubenthal, 2015, pp. 277-279).

\section{CONCLUSIONES Y DISCUSIÓN}

El 7 de julio de 2006 tuvo lugar la más significativa reforma de la GG que estableció una nueva distribución de competencias entre la federación y los Länder. A esta investigación interesó la ola de reformas y nuevas leyes de ejecución de la pena de prisión de adultos en Alemania. El panorama normativo de la ejecución de la pena de prisión de los adultos después de la reforma de 2006 quedó compuesto en Alemania de dos niveles: federal y estadual.

Una de las preguntas que se buscaba responder al iniciar el artículo era conocer en qué temáticas los criterios de la Ley Federal de 1976 y de la jurisprudencia del BVerfG han influido sobre las legislaciones estaduales. En torno a esta primera inquietud, podemos afirmar que hay una marcada influencia de la Ley Federal y la jurisprudencia del BVerfG en materia de control judicial, estatus jurídico del preso, consagración normativa de la separación entre hombre y mujeres, contacto con el mundo exterior, medidas disciplinarias y tipos de centros.

En materia de control judicial, la influencia de la Ley Federal de 1976 en las leyes estaduales es obvia al continuar el título relativo al control judicial de la ley vigente y vinculante para los Länder. El segundo tema donde la influencia de la Ley Federal y de la jurisprudencia del BVerfG es marcada es en materia del estatus jurídico del preso. Alemania claramente adopta el paradigma del Estado como garante del privado de libertad, considerando al preso como sujeto de derechos y a la administración penitenciaria acreedora de obligaciones de custodia, cuidado y tratamiento del privado de libertad. La preocupación de las leyes estaduales por los efectos negativos del encierro, así como la consagración de normas que vinculan el estatuto de derechos de la GG con los derechos de los presos dan cuenta de la relación del preso con el Estado. 
El contacto con el mundo exterior —en sus modalidades visitas, correspondencia escrita, telecomunicaciones, paquetes y encomiendas - es otro de los temas donde se evidencia la influencia de la Ley Federal de 1976. Los tipos de centros son otra materia donde las leyes estaduales siguen a la Ley Federal de 1976. Estos centros funcionan bajo la lógica de que la ejecución es un proceso que se inicia con el ingreso al penal y diseño del plan individualizado, y que se extiende hasta la puesta en libertad. Asimismo, los centros contemplan las modalidades de la ejecución - abierta o cerrada - y la aplicación de un régimen especial para los que necesiten terapia social.

La regulación de las medidas disciplinarias parece ser otra dimensión de influencia de la Ley Federal en las leyes de ejecución estaduales. La estrategia legislativa vinculada con establecer catálogos generales de normas de comportamiento y la exigencia general de culpabilidad por la infracción de la norma de comportamiento como fundamento de la sanción disciplinaria parecen ser la tónica en la gran mayoría de las legislaciones estaduales.

Con todo, la regulación de las medidas disciplinarias junto a la regulación del principio de separación y diferenciación destacan negativamente por su técnica legislativa. En otras palabras, en estas materias la crítica de la doctrina parece sugerir que la adhesión a la Ley Federal de 1976 sería más un problema que un aspecto positivo. Se estima que en estos temas los legisladores estaduales desaprovecharon la ocasión para regular la temática con mayor precisión, dando cuenta en detalle de las particularidades del grupo vulnerable que se desea privilegiar y de las conductas exigidas en el interior de las prisiones. Asimismo, el poco espacio que se le otorga a la defensa técnica en el proceso de aplicación de las medidas disciplinarias parece ser otra debilidad que las leyes estaduales no superaron.

Del desarrollo del artículo se puede constatar que hay otro grupo de temáticas donde la influencia de la Ley Federal y de la jurisprudencia del BVerfG no es tan clara, por lo que resulta necesario hacer matices o distinguir tendencias entre las legislaciones estaduales. Esto ocurre en materia de fines de la ejecución de la pena de prisión, salidas, tratamiento, trabajo y medidas de seguridad. En materia de fines, un grupo minoritario de legislaciones directamente se aleja del criterio fijado en 1976 y le entrega a la protección de la comunidad el mismo peso que a la reinserción social. Vinculado con lo anterior se encuentra el tema de las salidas, donde un grupo de legislaciones establece reglas especiales para determinados grupos de criminalidad. En el caso de delitos violentos, de connotación sexual y condenas a pena perpetua, se establecen plazos y criterios adicionales que limitan el acceso a las salidas. 
En materia de trabajo dentro de la cárcel, es posible apreciar dos tendencias: la que lo considera obligatorio y la que lo considera voluntario. En ambas opciones aparecen razonables condiciones que parecen disminuir los riesgos de esclavitud, abusos y daños sobre la persona de los trabajadores. En materia de tratamiento se abre una tenue tendencia que ahonda en el concepto mismo, pero que ha sido desarrollada por pocos estados federados.

El tema de las medidas de seguridad exigiría hacer una distinción entre las medidas de seguridad generales y las especiales. Se aprecia en el análisis de la sección segunda que, en materia de medidas de seguridad generales, parece existir una mayor adhesión por parte de las legislaciones estaduales a los criterios fijados en la materia por la Ley Federal de 1976. Sin embargo, en materia de medidas de seguridad especiales, existiría mayor innovación por parte de las legislaciones estaduales.

Otro de los objetivos que el presente artículo se planteaba al inicio era hacer un análisis crítico acerca de si la adhesión o distanciamiento de las leyes estaduales a los lineamientos y estándares de la Ley Federal de 1976 y a los estándares jurisprudenciales del BVerfG significa o no un avance con respecto a la normativa anterior. Como se mencionó, existirían en materia de medidas disciplinarias, de separación y de diferenciación serias dudas por parte de la doctrina en considerar la influencia de la Ley Federal de 1976 como positiva. Algo similar podría sostenerse en materia de fines y salidas. Con la incorporación de la protección de la colectividad como finalidad, se incluye en esta etapa otros fines del castigo como la incapacitación, retribución o prevención general. Con la reforma de 1976, los intereses preventivos generales tenían un tenue espacio en la etapa de ejecución, a través de los tiempos de cumplimiento mínimo dentro de la prisión que el legislador fijaba para solicitar las salidas o la sustitución de la sanción de prisión. El mínimo preventivo general necesario para que la sanción sea tomada en serio por la comunidad y el sujeto condenado se fijaba, para todo tipo de criminalidad, en los seis meses y en diez años para el presidio perpetuo.

Con la incorporación de la protección de la colectividad como finalidad se abre espacio a otro tipo de intereses, por ejemplo, eliminar el potencial criminal de los condenados asegurando la reclusión efectiva por el mayor tiempo posible. La incorporación de este tipo de finalidad en la etapa de ejecución puede apreciarse nítidamente en el establecimiento de nuevos plazos y requisitos en determinado grupo de delitos «criminalidad violenta y sexual» para limitar el acceso a salidas y sustitución. Esto resulta en extremo llamativo, implicando incluso problemas de constitucionalidad, en un sistema penal que, bajo la Ley Federal de 1976 y la jurisprudencia del BVerfG, había hecho esfuerzos por mantener una sola finalidad en la etapa de ejecución: «reinserción». Este distanciamiento marca uno de 
los principales quiebres con los lineamientos fijados y estándares de la Ley Federal y de la jurisprudencia del BVerfG.

Esta agravación del estándar en materia de flexibilización de la pena y, en términos más generales, la incorporación de otras finalidades que buscan proteger a la comunidad son reflejo de una tendencia más amplia que está impactando en algunos estados federados. Como explica Frisch, en los últimos años, se ha llegado a la convicción de que existe un grupo de criminalidad que no puede ser contrarrestada con los medios tradicionales del derecho penal, con autores que ya han sido objeto sin éxito de penas proporcionadas y medidas indulgentes en forma reiterada o múltiple. Existiría una nueva valoración sobre el actuar de los autores reincidentes peligrosos que realizan delitos sexuales, de drogas, o de agresión, entre otros, que fundamentaría una agravación en el derecho penal, con penas prolongadas y efectivas para la protección de víctimas. Esta nueva valoración, que podría explicar el por qué algunos estados federados se estarían alejando del criterio de la Ley Federal de 1976 y de los estándares del BVerfG, en todo caso, no estaría exenta de problemas. Por ejemplo, Frisch advierte que se corre el riesgo de que las agravaciones se extiendan no solo a aquellos autores reincidentes peligrosos, cuestión que sería abiertamente irrazonable y desproporcionada (2014, pp. 112-118).

Finalmente, otro aspecto que resulta cuestionable en las leyes estaduales es que se deniegue la salida aludiendo a razones preventivo especial positivas. Lo controvertido en el caso es que la evidencia demuestra que los mejores resultados preventivo especial positivos se pueden alcanzar fuera de la cárcel y no dentro de ella. Resulta difícil sostener, con toda la evidencia existente en torno a los perjuicios del encierro en el ser humano, que la prisión sí podría ser un escenario para llegar a conseguir algún tipo de efecto resocializador (Liebling \& Maruna, 2005). En todo caso, lo que sí tiene sentido al decidir las salidas - y que fue recogido por las leyes estaduales de la Ley Federal de 1976- es el análisis del comportamiento futuro del recluso en la comunidad. El ejercicio de prognosis resulta fundamental para orientar la decisión en torno a la concesión o no de las salidas. La prognosis centra el análisis en cómo será el desempeño del sujeto en la comunidad y no, como ocurre en algunas legislaciones latinoamericanas — como la chilena-, en cómo ha sido el comportamiento del sujeto dentro del recinto. En realidad, el comportamiento del sujeto dentro de la cárcel, entendido este según si ha sido o no objeto de medidas disciplinarias, nada nos dice sobre su comportamiento futuro (para más información, véase Salinero, Morales Peillard \& Castro Morales, 2017, pp. 842-843; Frisch \& Vogt, 1994, pp. 55-62).

EJECUCIÓN DE LA PENA DE PRISIÓN DE ADULTOS EN ALEMANIA: ANÁLISIS DE LAS LEYES ESTADUALES A LA LUZ DE LA LEY FEDERAL DE 1976 Y LA JURISPRUDENCIA DELTRIBUNAL CONSTITUCIONAL FEDERAL ALEMÁN (BVERFG)*

ADULT PRISON LAW IN GERMANY: ANALYSIS OF STATE LAWS IN THE LIGHT OF THE FEDERAL LAW OF 1976 AND GERMAN FEDERAL CONSTITUTIONAL COURT'S (BVERFG) CASE LAW 
Luego de hacerme cargo de las respuestas a las preguntas que motivaron este artículo, resulta necesario resaltar tres cuestiones generales, a saber: el diseño de sanciones penales en el derecho penal alemán, la estrategia legislativa que regula en leyes separadas la ejecución de la pena de prisión de adultos y adolescentes, y el sistema de control judicial de la pena de prisión alemán. Con respecto a lo primero, no deja de ser ejemplar cómo el sistema de sanciones alemán ha racionalizado su práctica restándole máximo protagonismo a la sanción de prisión. Los medios utilizados, me refiero a la multa y suspensión de la pena de prisión, han funcionado de forma efectiva reduciendo cómodamente la carga de trabajo del sistema de la ejecución de la sanción de prisión dentro del país (5\% de las sanciones penales en Alemania son pena de cárcel efectiva). Además, el país ha mantenido en los últimos veinte años una tasa de privados de libertad por cien mil habitantes muy baja (cerca de 80), que solo ha sido superada en la región por los países escandinavos. Para los países latinoamericanos, con sistemas de sanciones que privilegian la pena de prisión, crecimiento explosivo de las tasas de privados de libertad por cien mil habitantes y extremos niveles de hacinamiento, este tipo de experiencia comparada debe ser objeto de estudio y un paradigma digno de ser seguido (véase, Castro Morales, 2018).

En torno a la estrategia legislativa que regula en «leyes separadas» la ejecución de la pena de prisión de adultos y adolescentes, hay que resaltar lo acertado de la decisión, toda vez que el principio de separación obligaría a los Estados no solo a establecer un sistema de sanciones y proceso penal distinto de los adultos, sino, además, un sistema de ejecución de sanciones para los adolescentes. Todas estas dimensiones del sistema penal juvenil se colman con lógicas, principios y estándares distintos a los aplicados a los adultos. En este sentido, una ley que regule ambas temáticas corre altos riesgos de debilitar la especialidad, haciendo prevalecer las dinámicas del grupo imperado mayoritario, esto es, el de los adultos. Para países latinoamericanos que recientemente enfrentaron la modernización de sus sistemas penales juveniles, una cuestión pronta a debatir es la forma como se están ejecutando las sanciones penales juveniles en el interior de los países y cómo debería regularse de mejor manera la temática. Y este tipo de estrategias legislativas desarrolladas en la gran mayoría de los Länder debería ser considerado como referente a la hora de enfrentarnos con el mejoramiento de la etapa de ejecución en el caso de los adolescentes infractores.

Por último, en torno al control judicial alemán en la etapa de ejecución de la pena de prisión, considero que este debiera ser objeto de mayor atención por la doctrina latinoamericana. Es un modelo que se levanta como alternativa al de jueces de vigilancia penitenciaria instaurados en Francia, España y en algunos países latinoamericanos como Argentina y Bolivia. Bajo el modelo alemán de control judicial, la administración 
penitenciaria seguiría adoptando las decisiones dentro del recinto, pero toda acción u omisión que genere vulneración de derechos para el privado de libertad habilitará al juez de ejecución para conocer dicha vulneración. Se trata de un modelo distinto del de los jueces de vigilancia, donde el juez asume directamente buena parte de las decisiones que antiguamente le correspondían a la administración penitenciaria, ocasionando una serie de tensiones con la administración del recinto (Juanatey Dorado, 2016, pp. 241-249).

\section{REFERENCIAS}

Albrecht, H. (2013). §60, Absehen der Strafe. En U. Kindhäuser, U. Neumann \& H.-U. Paeffgen (Eds.), Strafgesetzbuch (4a ed., pp. 2181-2184). Baden-Baden: Nomos.

Bachmann, M. (2015). Gerichtlicher Rechtsschutz. En K. Laubenthal, N. Nestler, F. Neubacher \& T. Verrel, Strafvollzugsgesetz (12a ed., pp. 1340-1421). Berlín: C.H. Beck.

Benda, H. (2001a). Dignidad humana y derechos de la personalidad. En E. Benda, W. Maihofer, H. Vogel, K. Hesse \& W. Heyde (Eds.), Manual de derecho constitucional (2⿺ ed., pp. 117-144). Madrid: Marcial Pons.

Benda, H. (2001b). El Estado social de Derecho. En E. Benda, W. Maihofer, H. Vogel, K. Hesse \& W. Heyde (Eds.), Manual de derecho constitucional (2ª ed., pp. 487-559). Madrid: Marcial Pons.

Böhm, A. (1986). Strafvollzug (2a ed.). Fráncfort d.M.: Metzner.

Böhm, A. (2005). Erster Abschnitt: Anwendungsbereich §1. En H.-S. Schwind, A. Böhm y J.M. Jehle (Eds.), Strafvollzugsgesetz (pp. 63-66). Berlín: De Gruyter.

Callies, R.-P. \& Müller-Dietz, H. (2002). Strafvollzugsgesetz: Gesetz über den Vollzug der Freiheitsstrafe und der freiheitsentziehenden Maßregeln der Besserung und Sicherung mit ergänzenden Bestimmungen ( $9^{\mathrm{a}} \mathrm{ed}$.). Múnich: C.H. Beck.

Castro Morales, Á. (2018). Estándares de la Corte Interamericana de Derechos Humanos en materia de imputados y condenados privados de libertad. Anuario de Derechos Humanos, 14, 35-54. https://doi.org/10.5354/0718-2279.2018.49161

Cornel, H. (2009). Zum Begriff der Resozialisierung. En H. Cornel, G. KawamuraReindl, B. Maelicke \& B.-R. Sonnen (Eds.), Resozialisierung (pp. 27-60). BadenBaden: Nomos.

Cornel, H. (2018). Die Entwicklung des deutschen Strafvollzugs nach der Föderalismusreform des Jahres 2006 mit der Verlagerung der Gesetzgebungskompetenz auf die Bundesländer. Neue Kriminalpolitik, 30(1), 1620. https://doi.org/10.5771/0934-9200-2018-1-16

Drenkhahn, K. (2014). Personal contacts with the outside world and preparation for release. En K. Drenkhahn, K.M. Dudeck \& F. Dünkel (Eds.), Long-Term Imprisonment and Human Rights (pp. 363-373). Nueva York: Routledge. https://doi.org/10.4324/9781315774442 
Dünkel, F. (1996). Empirische Forschung im Strafvollzug: Bestandaufnahme und Perspektiven. Bonn: Forum Verlag Godesberg.

Dünkel, F. (2011) Werden Strafen immer härter? Anmerkungen zur strafrechtlichen Sanktionspraxis und zur Punitivität. En B. Bannenberg \& J.-M. Jehle (Eds.), Gewaltdelinquenz Lange Freiheitsentziehung Delinquenzverläufe. Neue Kriminologische Schriftenreihe (pp. 209-237). Mönchengladbach: Forum Verlag Godesberg.

Dünkel, F. (2013a). §38, Dauer der Freheitsstrafe. En U. Kindhäuser, U. Neumann $\&$ H.-U. Paeffgen (Eds.), Strafgesetzbuch (4a ed., pp. 1680-1721). Baden-Baden: Nomos.

Dünkel, F. (2013b). §57, Aussetzung des Strafrestes bei zeitiger Freiheitsstrafe. En U. Kindhäuser, U. Neumann \& H.-U. Paeffgen (Eds.), Strafgesetzbuch (4a ed., pp. 2078-2140). Baden-Baden: Nomos.

Dünkel, F. (2018). Strafvollzug. En D. Hermann \& A. Pöge (Eds.), Kriminalsoziologie. Handbuch für Wissenschaft und Praxis (pp. 399-438). BadenBaden: Nomos. https://doi.org/10.5771/9783845271842-398

Dünkel, F. \& Kühl, J. (2009). Neuregelung des Strafvollzugs in Hamburg. Anmerkungen zum Hamburger Strafvollzugs- und Jugendstrafvollzugsgesetz vom 8.7.2009. Neue Kriminalpolitik, 21(3), 82-86.

https://doi.org/10.5771/0934-9200-2009-3-82

Dünkel, F., Pruin, I., Beresnatzki, P. \& Treig, J. (2018). Vollzugsöffnende Maßnahmen und Entlassungsvorbereitung-Gesetzgebung und Praxis in den Bundesländern. Neue Kriminalpolitik, 30(1), 21-50.

https://doi.org/10.5771/0934-9200-2018-1-21

Dünkel, F. \& Rössner, D. (2001). Germany. En D. van Zyl Smit \& F. Dünkel (Eds.), Imprisonment today and tomorrow. International perspectives on prisoners' rights and prison conditions (2- ed., pp. 288-350). La Haya: Kluwer Law International.

Frisch, W. (2014). Los conceptos de pena y el desarrollo del derecho penal en Europa. En W. Frisch \& G. Freund, Cuestiones fundamentales del derecho penal (pp. 81-126). Lima: Jurista Editores.

Frisch, W. \& Vogt, T. (Eds.) (1994). Prognoseentscheidungen in der strafrechtlichen Praxis. Baden-Baden: Nomos.

Göppinger, H. (1997). Kriminologie (5ª ed.). Múnich: C.H. Beck.

Jehle, J.-M. (2015). Strafrechtspflege in Deutschland. Fakten und Zahlen. Mönchengladbach: Forum Verlag Godesberg.

Juanatey Dorado, C. (2016). Manual de derecho penitenciario. Madrid: Iustel.

Kaiser, G. \& Schöch, H. (2002). Strafvollzug. Ein Lehrbuch (5ª ed.). Heidelberg: C.F. Müller.

Kaiser, G. \& Schöch, H. (2003). Strafvollzug. Eine Einführung in die Grundlagen (5 ed.). Heidelberg: C.F. Müller. 
Koop, G. \& Kappenberg, B. (2009). Wohin fährt der Justizvoll-Zug? Strategien für den Justizvollzug von morgen. Lingen: Kriminalpädagogischer Verlag.

Landau, H. (2011). Grundgesetz und Strafvollzug. Menschenbild des Grundgesetzes und Umgang mit Straftätern. Forum Strafvollzug, 60 (3), 129-137.

Laubenthal, K. (1998). Strafvollzug (2a ed.). Berlín-Heidelberg: Springer. https://doi.org/10.1007/978-3-662-10082-0

Laubenthal, K. (2015). Strafvollzug (7ª ed.). Berlín-Heidelberg: Springer. https://doi.org/10.1007/978-3-642-54819-2

Liebling, A. \& Maruna, S. (2005). Introduction: the effects of imprisonment revisited. En A. Liebling \& S. Maruna (Eds.), The effects of imprisonment (pp. 1-32). Cullompton: Willan Publishing.

Marisken, L. (2018). Arbeit und Arbeitsentlohnung in den Länderstrafvollzugsgesetzen- Vollzugsrechtliche, verfassungs- und menschenrechtlichen Aspekte. Neue Kriminalpolitik, 30(1), 51-62.

https://doi.org/10.5771/0934-9200-2018-1-51

Martín Vida, M.A. (2006). La reforma del federalismo alemán. Una visión general. Teoría y Realidad Constitucional, 18, 337-350.

https://doi.org/10.5944/trc.18.2006.6731

Mika, M. (2018). Zehn Jahre Landesstrafvollzugsgesetzgebung - Eine kritische Betrachtung der besonderen Sicherungs- sowie der Disziplinarmaßnahmen. Neue Kriminalpolitik, 30(1), 63-76. https://doi.org/10.5771/0934-9200-2018-1-63

Müller-Dietz, H. (2008). Strafvollzug und Verfassungsrecht. En F. Dünkel, K. Drenkhahn \& C. Morgenstern (Eds.), Humanisierung des Strafuollzugs -Konzepte und Praxismodelle (pp. 11-34). Mönchengladbach: Forum Verlag Godesberg.

Neubacher, F. (2015a). Einleitung. En K. Laubenthal, N. Nestler, F. Neubacher \& T. Verrel, Strafvollzugsgesetz (12a ed., pp. 1-22). Berlín: C.H. Beck.

Neubacher, F. (2015b). Vollzugsgrundsätze. En K. Laubenthal, N. Nestler, F. Neubacher \& T. Verrel, Strafvollzugsgesetz (12a ed., pp. 23-87). Berlín: C.H. Beck.

Neubacher, F (2017). Kriminologie ( $3^{\mathrm{a}}$ ed.). Baden-Baden: Nomos. https://oi.org/10.5771/9783845274171

Ostendorf, H. (2012). Historische Entwicklung des Jugendstrafvollzugs. En H. Ostendorf (Ed.), Jugendstrafvollzugsrecht. Kommentierende Darstellung der einzelnen Jugendstrafuollzugsgesetze (2a ed., pp. 29-33). Baden-Baden: Nomos.

Ostendorf, H. \& Drenkhahn, K. (2017). Jugendstrafrecht. Baden-Baden: Nomos. https://doi.org/10.5771/9783845278490

Roxin, C. (1997). Derecho Penal, Parte General, Tomo I: Fundamentos. La estructura de la teoría del delito (Trad. D.M. Luzón Peña, M. Díaz y García Conlledo, y J. de Vicente Remesal). Madrid: Civitas.

Salinero, S., Morales Peillard, A.M. \& Castro Morales, A. (2017). Análisis comparado y crítico de las alternativas a las penas privativas de libertad. La

\section{EJECUCIÓN DE LA PENA DE PRISIÓN DE ADULTOS EN ALEMANIA: ANÁLISIS DE LAS LEYES \\ ESTADUALES A \\ LA LUZ DE LA LEY FEDERAL DE 1976 Y LA JURISPRUDENCIA DEL TRIBUNAL CONSTITUCIONAL FEDERAL ALEMÁN (BVERFG)* \\ ADULT PRISON LAW IN GERMANY: ANALYSIS OF STATE LAWS IN THE LIGHT OF THE FEDERAL LAW OF 1976 AND GERMAN FEDERAL CONSTITUTIONAL COURT'S (BVERFG) CASE LAW}


experiencia española, inglesa y alemana. Revista Política Criminal, 12(24), 786864. https://doi.org/10.4067/s0718-33992017000200786

Vormbaum, T. (2009). Einführung in die moderne Strafrechtsgeschichte. BerlínHeidelberg: Springer. https://doi.org/10.1007/978-3-540-75955-3

Walter,J.(2015).DieRegelungendesMusterentwurfzumLandesstrafvollzugsgesetz (ME) zu Disziplinarmaßnahmen. En T. Rotsch, J. Brüning \& J. Schady (Eds.), Strafrecht - Jugendstrafrecht - Kriminalprävention in Wissenschaft und Praxis. Festschrift für Heribert Ostendorf zum 70. Geburtstag am 7. Dezember 2015 (pp. 917 932). Baden-Baden: Nomos. https://doi.org/10.5771/9783845265384-917

Walter, M. (1999). Strafvollzug (2a ed.). Stuttgart: Richard Booberg.

Walter, J. \& Kirchner, G. (2012). Organisation. En H. Ostendorf (Ed.), Jugendstrafvollzugsrecht. Kommentierende Darstellung der einzelnen Jugendstrafvollzugsgesetze (2a ed., pp. 703-742). Baden-Baden: Nomos.

Wirth, W. (2005). Vierter Abschnitt. Vollzugsbehörden. §141: Differenzierung. En H.-S. Schwind, A. Böhm \& J.-M. Jehle (Eds.), Strafvollzugsgesetz (pp. 865878). Berlín: De Gruyter.

Witos, G., Staiger, I. \& Neubacher, F. (2014). Videoüberwachung im Strafvollzug. Neue Kriminalpolitik, 26(4), 159-379.

https://doi.org/10.5771/0934-9200-2014-4-359

Zysman Quirós, D. (2013). Sociología del castigo: Genealogía de la determinación de la pena. Buenos Aires: Didot.

\section{Jurisprudencia, normativa y otros documentos legales}

Strafgesetzbuch der Deutschen Demokratischen Republik [Código Penal de la República Democrática Alemana], modificado por última vez el 26 de enero de 1998.

Gesetz über den Vollzug der Freiheitsstrafe und der Jugendstrafe (Bayerisches Strafvollzugsgesetz - BayStVollzG). Ley penitenciaria de Baviera del 10 de diciembre de 2007.

Gesetz über den Vollzug der Freiheitsstrafe (Hamburgisches Strafvollzugsgesetz HmbStVollzG). Ley penitenciaria de Hamburgo del 14 de julio de 2009.

GesetzbuchüberdenJustizvollzuginBaden-Württemberg(Justizvollzugsgesetzbuch - JVollzGB). Ley penitenciaria de Baden Wurtemberg del 10 de noviembre de 2009.

Hessisches Strafvollzugsgesetz (HStVollzG). Ley penitenciaria de Hesse del 28 de junio de 2010.

Gesetz über den Vollzug der Freiheitsstrafe im Saarland (Saarländisches Strafvollzugsgesetz - SLStVollzG). Ley penitenciaria del Sarre del 24 de abril de 2013. 
Gesetz über den Vollzug der Freiheitsstrafe in Mecklenburg-Vorpommern (Strafvollzugsgesetz Mecklenburg-Vorpommern - StVollzG M-V). Ley penitenciaria de Mecklemburgo Pomerania Occidental del 7 de mayo de 2013.

Landesjustizvollzugsgesetz (LJVollzG). Ley penitenciaria de Renania-Palatinado del 8 de mayo de 2013.

Sächsisches Strafvollzugsgesetz (SächsStVollzG). Ley penitenciaria de Sajonia del 16 de mayo de 2013.

Thüringer Justizvollzugsgesetzbuch (ThürJVollzGB). Ley penitenciaria de Turingia del 27 de febrero de 2014.

Niedersächsisches Justizvollzugsgesetz (NJVollzG). Ley penitenciaria de Baja Sajonia del 8 de abril de 2014.

Gesetz über den Vollzug von Freiheitsstrafe, der Jugendstrafe und der UntersuchungshaftimLand Brandenburg (BrandenburgischesJustizvollzugsgesetz -BbgJVollzG). Ley penitenciaria de Brandeburgo del 24 de abril de 2014.

Gesetz zur Neuregelung des Vollzugs der Freiheitsstrafe in der Freien Hansestadt Bremen. Ley penitenciaria de Bremen del 25 de noviembre de 2014.

Gesetz zur Regelung des Vollzuges der Freiheitsstrafe und zur Änderung des Jugendstrafvollzugsgesetzes in Nordrhein-Westfalen (StVollzG NRW). Ley penitenciaria de Renania del Norte-Westfalia del 13 de enero de 2015.

Gesetzes zur Weiterentwicklung des Justizvollzuges in Sachsen-Anhalt. Ley penitenciaria de Sajonia-Anhalt del 18 de diciembre de 2015.

Berliner Strafvollzugggesetz (StVollzG Bln). Ley penitenciaria de Berlín del 16 de abril de 2016.

Gesetzes über den Vollzug der Freiheitsstrafe in Schleswig-Holstein und zur Schaffung eines Justizvollzugsdatenschutzgesetzes. Der Landtag SchleswigHolsteins beschloss am 21. Juli 2016 das Strafvollzugsgesetz, welches am 9. Januar 2017 in Kraft treten soll. Gesetz über den Vollzug der Freiheitsstrafe in Schleswig - Holstein (Landesstrafvollzugsgesetz Schleswig - Holstein - LStVollzG SH). Ley penitenciaria de Schleswig-Holstein. 